\title{
Is there Swissness in investment decision behavior and investment competence?
}

\author{
Kremena Bachmann' ${ }^{1}$ Thorsten Hens ${ }^{1,2}$
}

Published online: 26 July 2016

(C) Swiss Society for Financial Market Research 2016

\begin{abstract}
Based on a large international survey, we analyze how German-, French-, and Italian-speaking residents of Switzerland differ in their investment decision behavior and investment competence compared to their closest neighbors abroad who speak the same language. Although language may be closer to the individual self than country of residence, we find that there are greater similarities in the decision behavior of residents of Switzerland speaking different languages than there are between these and their linguistically closest neighbors abroad. These similarities hold also for the ability to avoid investment mistakes, which is stronger in all Swiss regions compared to the linguistically closest regions abroad. The Swissness in investment competence is more likely to be emotionally than knowledge driven and is associated with regional differences in the relationships with investment advisors.
\end{abstract}

Keywords Behavioral finance $\cdot$ Investment mistakes · Cultural finance

JEL Classification D19 $\cdot$ Z10

We thank the Baloise Group for financial support in collecting the data. Comments provided by Christian Dreyer, Marc-Oliver Rieger, Mei Wang, Manish Gupta, Michal Dzielinski, the participants of the 2015 annual meeting of the Swiss Society of Economics and Statistics, and two anonymous referees are greatly appreciated.

$凶$ Thorsten Hens

thorsten.hens@bf.uzh.ch

Kremena Bachmann

kremena.bachmann@bf.uzh.ch

1 Department of Banking and Finance, University of Zurich, Plattenstrasse 32, 8032 Zurich, Switzerland

2 Norwegian School of Economics and Business Administration, Helleveien 30, 5045 Bergen, Norway 


\section{Introduction}

Traditionally, economists have assumed that economic behavior is independent of culture. However, as Fehr and Ho (2011) note, this view is questionable in light of a growing literature showing that economic behavior can be endogenous and can be shaped by societal and cultural influences (e.g., Bowles 1998; Henrich 2000; Eugster et al. 2011; Hoff et al. 2011).

In this paper, we analyze whether investment decision behavior and investment competence in Switzerland differs from that in neighboring countries. By "investment competence", we mean the ability to avoid the investment mistakes that usually occur when people make emotional decisions or use heuristics or "rules of thumb" to compensate for lack of knowledge or experience. Based on a large survey carried out in three linguistically different parts of Switzerland as well as in neighboring countries, we find that in their decision behavior, Swiss are more similar to each other than to their neighbors abroad who speak the same language. These similarities hold also for the ability to avoid investment mistakes, which is stronger in all Swiss regions compared to the linguistically closest regions abroad. The Swissness in investment competence is more likely to be emotionally than knowledge driven and is associated with regional differences in the relationships with investment advisors. We conclude that there is Swissness in the investment decision behavior and investment competence. Although language might be closer to the individual self than country of residence, our results suggest that in countries with multiple language identities there still may be nationallevel traits that impact investment decision behavior and investment competence.

Previous research on the existence of Swissness concludes that Swissness is an overarching sense of collective identity that competes with the sense of identity based on lower (linguistic) level characteristics. With respect to the latter, Longchamp (2002) finds that Swiss living in different language regions differ significantly among each other with respect to value orientation. Additionally, a survey by Swiss national television shows that the majority of Swiss citizens perceive important regional differences in mentality that are due to the different languages (Miauton and Reymond 1998). The economic consequences of such differences become evident when looking at the different attitudes held toward government-provided social insurances (Eugster et al. 2011), employment (Brügger et al. 2009), and the valuation of publicly provided goods or taxes (Eugster and Parchet 2013). In terms of collective identity, Longchamp (2002) finds that despite value fragmentation, Swiss citizens still feel that they "belong" to Switzerland, rather than to their language region or canton (Longchamp 2002, p. 20). Moreover, a recent survey of eligible Swiss voters shows that Swiss define themselves primarily as Swiss citizens, rather than by their communities and language regions (Schiendorfer 2013). The collective identity of the Swiss is also evident in an international context. McRae (1983) finds that a clear majority in all three language communities feel "strongly attached" or "very strongly attached" to Switzerland compared to their attachment to their linguistically closest neighbors abroad, that is, cross-language bonding in Switzerland appear stronger than cross-border bonding. This supports the proposition of King (1997) that "Swiss have ... customs, cultural traditions and political institutions that bind them closer to one another than to people of France, Germany or Italy living just across the border and speaking the same lan- 
guage." In this paper we analyze whether closer bonding is also found for investment decision-making, which can be influenced by emotion and the way people make use of information.

In the field of psychology, the impact of emotions and cognition is assumed to be universal. However, Nisbett et al. (2001) propose that the underlying processes vary between different groups of individuals. Empirically, the issue is not yet resolved. Some studies find that emotions such as regret affect individuals in a similar way (Gilovich et al. 2003). Moreover, alternative representations of information seem to affect people in a similar way (Levin et al. 2001). Other studies suggest that there are significant cultural differences in the way people perceive and use information. These differences are evident in the estimated precision of own predictions (Acker and Duck 2008; Wright and Phillips 1980; Yates et al. 1989, 1998), in the tendency to rely on stereotypes in probability judgments (Spina et al. 2010), and also in the way people respond to different representations of information (Levinson and Peng 2007; Wang and Fischbeck 2004).

In addition to differences in the emotional and cognitive drivers of decision-making, there is evidence that the people of different countries vary in the way they deal with financial questions, such as questions on compound interest, inflation, and risk diversification (for an overview, see Lusardi and Mitchell 2013). In the case of Switzerland, Brown and Graf (2013) find that the financial literacy of German-speaking Swiss is high and comparable to that in Germany.

West and Graham (2004) suggest that the language spoken is important in explaining differences in decision behavior. Nisbett (2003) provides evidence for the notion that the language learned influences cognitive habits. He observes that Americans are more object and fact oriented than Asians, which allows Asians to be better at seeing relationships between events. For example, Americans tend to see trends as likely to continue, whereas Asians see trends as signs that they will reverse. This evidence supports the approach of Stulz and Williamson (2003), who use a common language to capture differences between entities. Recently, Chen (2013) analyzed whether the language that people use influences their investment behavior. He finds that individuals speaking a language with an obligatory future-time reference (e.g., French and Italian), treat future rewards as more distant and take fewer future-oriented actions, such as retirement saving, than individuals speaking a language that does not require attending to the time when speaking (e.g., German).

If language reflects some deeper differences in the processes of the mind that affect investment decisions or reflects some cultural preoccupations in the way people think, then we should be able to observe significant difference across language regions, even within national borders. Comparing these differences with differences across countries will allow discovering whether there is a Swissness that acts as a complement to regional identities based on different languages.

\section{Methods}

The study is based on an online-questionnaire consisting of three parts. In the first part, the participants were asked to state their age, gender, and their permanent place 


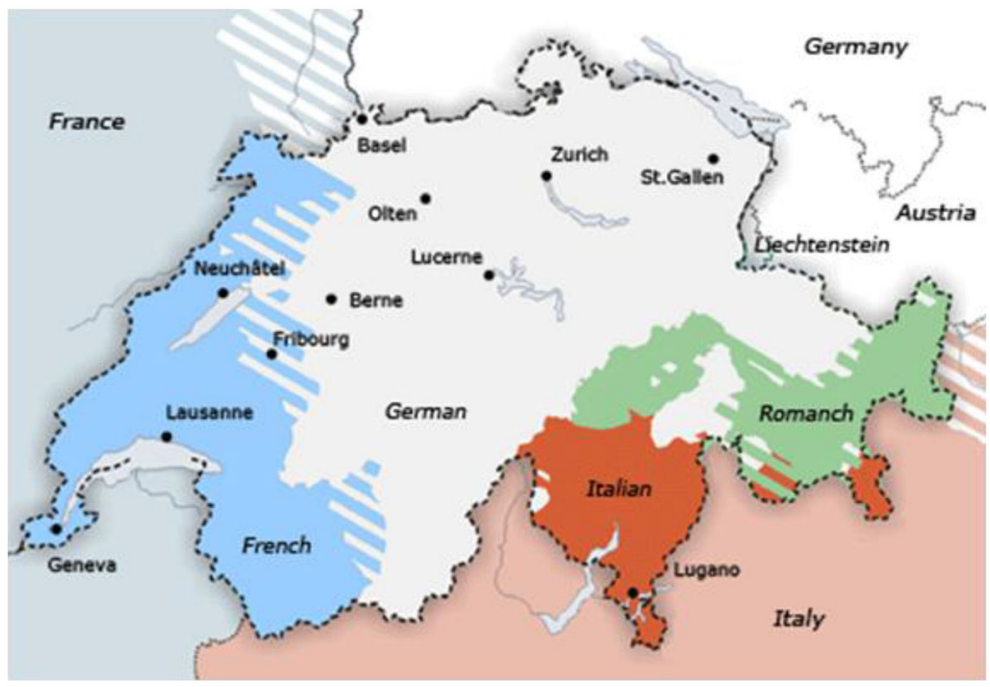

Fig. 1 Language regions in Switzerland. Source: http://www.qualitative-research.net/index.php/fqs/ article/view/13/27

of residence. These data were used to balance the sample of participants so that the proportion of males and females is approximately equal and the age of participants is between 25 and 70 years. Place of residence was used to restrict the sample abroad to neighboring regions of Switzerland, which is expected to increase the homogeneity between Swiss and non-Swiss. The second part of the survey consists of questions evaluating the participants' investment experience and competence. The last part of the survey collects participants' socioeconomic and demographic characteristics.

\subsection{Participants}

The participants of our study are individuals living permanently in Switzerland and in the closest regions of the border countries Germany, France, and Italy (see Fig. 1). ${ }^{1}$ Switzerland is a federation of 26 cantons that can be divided into four regions based on the cantons' official language: German, French, Italian, or Romanch. Some cantons are officially bilingual, but there are clearly defined language regions (German in northern, central, and eastern Switzerland, French in western Switzerland, Italian in southern Switzerland, and Romanch in southeastern Switzerland; see Fig. 1). In this study, we focus on the main languages German, French, and Italian as only $1 \%$ of the Swiss population speaks Romanch, a language unique to Switzerland, and everyone who speaks that language is perfectly able to speak German, too.

The official languages of Switzerland are used mainly for written communication. In everyday communication, Swiss use dialects (Swiss-German, Swiss-French, and Swiss-Italian). Although Germans usually have difficulty understanding Swiss-

\footnotetext{
1 We chose the regions Baden-Wuerttemberg and Bayern in Germany, Lombardia, Piemonte, and Veneto in Italy, and Alsace, Franchecomte, and Rhone-Alps in France.
} 
German, the linguistic differences between Swiss-French and French and between Swiss-Italian and Italian are negligible. Most Swiss live in monolingual cantons with clear language borders and thus language contact between French, German, Italian, and Romanch speakers is limited. Most Swiss people rarely read newspapers or listen to news in a language other than their own, meaning that Swiss living in different language regions receive information from media systems that take different approaches of news reporting (Esser and Umbricht 2013), which may have implications for investment attitudes.

We used professional market research agencies to recruit samples of participants in each region. ${ }^{2}$ We made sure that all participants speaking the same language were given the same version of the questions. Professional interpreters prepared the French and the Italian versions of the questions.

We decided to balance the sample of participants in terms of age and gender with no restrictions on professional background. Subsequent comparisons of individual characteristics with potential impact on investment competence revealed that the sample well represents the characteristics of permanent Swiss residents (see Sect. 2.4).

In our analysis, we distinguish between six groups of respondents based on their permanent place of residence and the language they speak: Swiss-German (SwissG), Swiss-French (SwissF), Swiss-Italian (SwissI), German (G), French (F), and Italian (I). We call participants with permanent place of residence in Switzerland "Swiss" and participants living outside Switzerland "non-Swiss", although we cannot exclude the possibility that participants may have multiple citizenship.

The participants received a fixed payment for their participation in the study or a chance to win a prize of comparable value. We do not expect that this difference in compensation will matter for the results, since the compensation was paid upon completing the survey and was in no way connected to the way the questions were answered. Indeed, in a pre-study we found that different compensations affect motivation for participating in the study, but have no significant effect on the answers.

\subsection{Eliciting investment competence}

Our questions eliciting individual investment competence are motivated by the vast research on behavioral and household finance documenting that individual investors make serious investment mistakes. Among the various evidence are findings that households tend to sell winners too early and hold losers too long (Odean 1998; Shefrin and Statman 1985), trade too much (Barber and Odean 2000), and hold underdiversified portfolios (Blume and Friend 1975; Goetzmann and Kumar 2008; Kelly 1995). As a result, the average retail investor tends to underperform the market (Barber et al. 2009).

\footnotetext{
2 The market research agencies use panels comprising individuals who have agreed to participate in online surveys. The participating individuals have a variety of professional backgrounds and experience in various industries. The target participants receive information on the goal of the study, general information on the questions, and an estimate of the maximum amount of time required to answer the questions. Based on this information, participants decide whether or not to participate in the survey. Compensation is received upon completing the survey.
} 
To develop a better understanding of the drivers of these mistakes, behavioral finance studies analyze the decision behavior of individuals in controlled experimental settings. These studies find that individuals' behavior does not comport with rational decision-making. Regarding the tendency to sell winners too early and hold losers too long (also known as the "disposition effect"), Summers and Duxbury (2012) find that the effect cannot be explained by different preferences for gains and losses but instead by the elation felt from realizing a gain and the regret experienced due to selling at a loss. Barberis and Xiong (2012) provide a formal model for this phenomenon. Summers and Duxbury (2012) also observe that these emotions motivate people to increase risk taking after losses in order to break even. Using data on the shareholdings and transactions of all investors in the Finnish stock market, Lehenkari (2012) confirms that individual investors hold onto their losers due to anticipated regret over losses and a reluctance to admit that the initial buying decision was a mistake. We use the following three questions to evaluate the emotional drivers of individual risk-taking behavior after gains and losses.

Question (risk taking after losses):

"How do you rate the correctness of the following decision rule 'After very large losses one should take more risks to break even' (a) always hold, (b) often hold, (c) only sometimes hold, (d) never hold, (e) I cannot decide."

Question (behavior after losses):

"Suppose you bought a financial asset at CHF/EUR 100. The market value of your investment is now at CHF/EUR 80. What would you do? (a) I would buy more, because I can get the asset for a lower price. (b) I would sell the asset, because I was not successful. (c) I would not sell the asset, because I would need to realize a loss. (d) I would reconsider the investment idea."

Question (behavior after gains):

"Suppose you bought a financial asset at CHF/EUR 100. The market value of your investment is now at CHF/EUR 150. What would you do? (a) I would realize the gain, i.e., sell the asset. (b) I would buy more, because I was successful. (c) I would reconsider the investment idea."

Previous gains and losses also affect the risk-taking behavior of professional traders. For example, Liu et al. (2010) observe that professional traders take more risks after gains. The strategy of repeating choices that produced favorable outcomes in the past can be successful if the traders have some information advantage, but the authors fail to find evidence of superior performance. In an experimental setting, Charness and Levin (2005) find that individuals repeat choices that had favorable outcomes in the past even if doing so is contrary to Bayesian reasoning. The following question evaluates the importance of previous gains as well as the importance of current positive trends. We assume that participants without any investment experience do not have any timing ability so that reliance on a positive trend can lead to superior performance only by chance.

Question (reasons for continuing investing):

"Suppose you decided to make a certain investment. Which of the following factors are the most important for you to keep the investment? (a) That I made a gain with the investment. (b) That the market value of the investment follows a positive trend at 
the moment. (c) That the investment idea is still valid. (d) I cannot decide because I do not have investment experience."

The tendency to repeat choices that have produced favorable outcomes in the past may also affect financial planning. People may avoid dealing with financial planning questions until losses occur. However, losses drive emotions of regret, which is not conducive to foster rational decisions (Summers and Duxbury 2012). Postponing planning can be suboptimal as well because households may not have enough time to accumulate the financial capital that will be necessary to meet their financial needs later. The following question evaluates the financial planning attitudes of the participants in our sample.

Question (financial planning):

"Which statement about the planning and monitoring of your financial situation describes best your attitude? (a) I monitor my financial situation regularly. (b) I review my financial situation only when losses occur. (c) I try to avoid dealing with my financial situation because I feel uncertain in financial decisions. (d) I often postpone the planning of my financial situation because my priorities change very often."

The second investment mistake we address is the one involving individual investors trading too much, that is, their trading activity and trading performance are not positively correlated (Barber and Odean 2000). We hypothesize that people engage in active trading because they have a wrong perception of randomness. According to the choice anomaly known as "probability matching", people predict random events in proportion to the probability of their occurrence (for a review, see Vulkan 2000). This strategy is suboptimal because the probability for accurate predictions by following this strategy is lower than in the case of always predicting the event with the higher probability. In the context of investments, probability matching motivates excessive trading, that is, active trading on a random walk when a buy-and-hold strategy is optimal. The following question evaluates this attitude.

Question (active versus passive investment choice):

"The price of a stock changes randomly. Suppose that you expect that the price of the stock will increase in more than half of the cases. Which strategy would you prefer? (a) I buy and hold the stock as long as I do not need the money. (b) I buy and wait until I made a certain gain, then I sell and buy again when the price falls."

We further hypothesize that excessive trading may be driven by a misperception of the drivers of investment success. While Brinson et al. (1986) find that strategic asset allocation explains more than $90 \%$ of investment success, people may think that stock picking and market timing drive performance. The news media, which usually discuss the performance of single assets or asset classes, can cultivate this misperception. The following question assesses whether the participants have enough investment knowledge to overcome the misperception. 


\section{Question (performance drivers):}

"Which of the following factors has the greatest contribution to investment success? (a) The long-term split of the wealth among different asset classes. (b) The short-term over- and under-weighting of asset classes. (c) The product choice within the asset classes."

Investment knowledge can also help in assessing the risk-reward potential of different asset classes, which can be strongly biased by information that is easily available in the memory such as information from the recent past (Tversky and Kahneman 1973).

Question (past long-term reward):

"Which of the following asset classes had the highest return in the long-run? (a) Cash, (b) gold, (c) bonds, (d) real estate, (e) stocks, (f) alternative investments (commodities, hedge funds, private equity)."

Question (past short-term risk):

"Which of the following asset classes had the highest risk in the short-run? (a) Cash, (b) gold, (c) bonds, (d) real estate, (e) stocks, (f) alternative investments (commodities, hedge funds, private equity)."

Finally, we investigate whether our participants are aware that their portfolios underperform due to under-diversification, as documented empirically (Blume and Friend 1975; Goetzmann and Kumar 2008; Kelly 1995).

Question (portfolio size):

"How many stocks do you need to achieve a good distribution of the risks in your portfolio with stocks? (a) 1-5 stocks, (b) 5-10 stocks, (c) more than 10 stocks."

Table 1 presents the regional distribution of the provided answers to all these questions, and reveals that participants in all regions have a clear preference for a certain answer. However, there are considerable regional differences in the distribution of answers.

In the analysis that follows, we ask whether there is Swissness in decision behavior, that is, whether the differences in the distribution of answers are smaller among Swiss speaking different languages than they are among participants speaking the same language but living in different countries. Afterward, we evaluate the answers to each question and analyze whether there is Swissness in the ability to avoid investment mistakes.

\subsection{Control variables}

As control variables we include demographic and socioeconomic characteristics as well as proxies for industry differences. Most of our demographic and socioeconomic variables are also used in studies analyzing cross-cultural differences in decisions driven by behavioral biases as well as in studies of financial literacy. The socioeconomic characteristics have also been used as proxies for investment experience and there is some empirical evidence suggesting that investment experience is relevant for avoiding certain behavioral biases (Koestner et al. 2012). The socioeconomic characteristics include household financial wealth and income as well as real estate ownership and job position. We expect that wealthier participants face less restriction in gaining investment experience. Conversely, we expect that low-income participants are more 
Table 1 Regional distribution of answers

\begin{tabular}{|c|c|c|c|c|c|c|c|}
\hline & SwissG & SwissF & SwissI & G & $\mathrm{F}$ & $\mathrm{I}$ & All \\
\hline \multicolumn{8}{|c|}{ Risk taking after losses } \\
\hline (a) (always true) & 0.6 & 0.5 & 1.0 & 1.9 & 3.0 & 4.2 & 1.8 \\
\hline (b) (mostly true) & 3.0 & 4.5 & 7.8 & 7.5 & 14.1 & 16.0 & 8.1 \\
\hline (c) (seldom true) & 37.8 & 31.2 & 35.0 & 36.0 & 36.1 & 47.6 & 38.2 \\
\hline (d) (never true) & 36.1 & 42.6 & 33.0 & 38.5 & 23.9 & 16.8 & 31.8 \\
\hline (e) (experience) & 22.5 & 21.3 & 23.3 & 16.1 & 23.0 & 15.4 & 20.1 \\
\hline$N$ & 701 & 202 & 103 & 361 & 305 & 357 & 2029 \\
\hline \multicolumn{8}{|l|}{ Behavior after losses } \\
\hline (a) (buy) & 12.1 & 8.4 & 9.7 & 15.0 & 14.1 & 21.6 & 14.1 \\
\hline (b) (sell) & 3.3 & 2.5 & 3.9 & 8.3 & 13.1 & 11.2 & 7.0 \\
\hline (c) (hold) & 35.3 & 51.5 & 41.8 & 31.0 & 48.5 & 42.3 & 39.7 \\
\hline (d) (check idea) & 49.3 & 37.6 & 44.7 & 45.7 & 24.3 & 24.9 & 39.2 \\
\hline$N$ & 702 & 202 & 103 & 361 & 305 & 357 & 2030 \\
\hline \multicolumn{8}{|l|}{ Behavior after gains } \\
\hline (a) (sell) & 58.4 & 57.0 & 69.6 & 62.3 & 59.3 & 72.0 & 62.1 \\
\hline (b) (buy) & 8.8 & 10.5 & 7.8 & 14.7 & 20.0 & 12.0 & 12.2 \\
\hline (c) (check idea) & 32.9 & 32.5 & 22.6 & 23.0 & 20.7 & 16.0 & 25.7 \\
\hline$N$ & 697 & 200 & 102 & 361 & 305 & 357 & 2022 \\
\hline \multicolumn{8}{|c|}{ Reasons for continuing investing } \\
\hline (a) (gain) & 13.0 & 18.0 & 15.5 & 19.4 & 32.1 & 23.8 & 19.6 \\
\hline (b) (trend) $)^{\mathrm{a}}$ & 19.8 & 13.0 & 36.9 & 30.2 & 20.7 & 42.3 & 25.9 \\
\hline (c) (idea) & 40.3 & 24.0 & 16.5 & 29.9 & 11.5 & 18.2 & 27.4 \\
\hline (d) (experience) & 26.9 & 45.0 & 31.1 & 20.5 & 35.7 & 15.7 & 27.1 \\
\hline$N$ & 698 & 200 & 103 & 361 & 305 & 357 & 2024 \\
\hline \multicolumn{8}{|l|}{ Financial planning } \\
\hline (a) (check) & 73.8 & 69.5 & 68.9 & 82.0 & 85.3 & 81.2 & 77.6 \\
\hline (b) (losses) & 3.0 & 5.5 & 5.8 & 5.8 & 3.3 & 5.0 & 4.3 \\
\hline (c) (uncertain) & 14.1 & 15.0 & 16.5 & 6.9 & 5.9 & 7.0 & 10.6 \\
\hline (d) (postpone) & 9.1 & 10.0 & 8.7 & 5.3 & 5.6 & 6.7 & 7.5 \\
\hline$N$ & 702 & 200 & 103 & 361 & 305 & 357 & 2028 \\
\hline \multicolumn{8}{|c|}{ Trading on a random walk } \\
\hline (a) (buy and hold) & 42.4 & 42.4 & 32.4 & 35.5 & 33.4 & 30.5 & 37.2 \\
\hline (b) (trade) & 57.6 & 57.6 & 67.7 & 64.5 & 66.6 & 69.5 & 62.8 \\
\hline$N$ & 682 & 198 & 102 & 361 & 305 & 357 & 2005 \\
\hline \multicolumn{8}{|l|}{ Performance drivers } \\
\hline (a) (strategic) & 77.8 & 76.7 & 73.3 & 66.2 & 52.1 & 71.4 & 70.4 \\
\hline (b) (tactic) & 6.5 & 4.0 & 5.7 & 17.2 & 11.2 & 10.4 & 9.5 \\
\hline (c) (selection) & 15.8 & 19.3 & 21.0 & 16.6 & 36.7 & 18.2 & 20.1 \\
\hline$N$ & 697 & 202 & 105 & 361 & 305 & 357 & 2027 \\
\hline
\end{tabular}


Table 1 continued

\begin{tabular}{|c|c|c|c|c|c|c|c|}
\hline & SwissG & SwissF & SwissI & G & $\mathrm{F}$ & I & All \\
\hline \multicolumn{8}{|c|}{ Past long-term reward } \\
\hline (a) (cash) & 2.4 & 1.0 & 1.9 & 11.1 & 6.9 & 8.1 & 5.4 \\
\hline (b) (gold) & 28.3 & 31.2 & 28.6 & 34.9 & 32.5 & 22.4 & 29.4 \\
\hline (c) (bonds) & 13.0 & 7.8 & 9.5 & 2.5 & 3.6 & 13.7 & 9.2 \\
\hline (d) (real estate) & 21.0 & 37.1 & 42.9 & 22.7 & 45.6 & 38.7 & 30.8 \\
\hline (e) (stocks) & 25.8 & 16.6 & 14.3 & 23.0 & 5.3 & 9.2 & 17.8 \\
\hline (f) (alt. inv.) & 9.5 & 6.3 & 2.9 & 5.8 & 6.2 & 7.8 & 7.4 \\
\hline$N$ & 706 & 205 & 105 & 361 & 305 & 357 & 2039 \\
\hline \multicolumn{8}{|l|}{ Past long-term risk } \\
\hline (a) (cash) & 2.4 & 8.3 & 0.0 & 5.8 & 10.8 & 9.8 & 6.0 \\
\hline (b) (gold) & 2.4 & 1.0 & 1.9 & 5.3 & 3.3 & 3.4 & 3.0 \\
\hline (c) (bonds) & 2.6 & 3.4 & 4.8 & 3.3 & 7.2 & 9.2 & 4.8 \\
\hline (d) (real estate) & 5.0 & 3.9 & 3.8 & 7.5 & 9.5 & 5.3 & 6.0 \\
\hline (e) (stocks) & 42.1 & 36.1 & 53.3 & 45.2 & 52.8 & 56.3 & 46.7 \\
\hline (f) (alt. inv.) & 45.6 & 47.3 & 36.2 & 33.0 & 16.4 & 16.0 & 33.5 \\
\hline$N$ & 706 & 205 & 105 & 361 & 305 & 357 & 2039 \\
\hline \multicolumn{8}{|l|}{ Portfolio size } \\
\hline (a) $(1-5)$ & 15.5 & 20.9 & 22.1 & 25.2 & 34.8 & 38.7 & 25.1 \\
\hline (b) $(5-10)$ & 52.8 & 54.7 & 52.9 & 57.6 & 44.3 & 44.3 & 51.1 \\
\hline (c) $(>10)$ & 31.7 & 24.4 & 25.0 & 17.2 & 21.0 & 17.1 & 23.8 \\
\hline$N$ & 691 & 201 & 104 & 361 & 305 & 357 & 2019 \\
\hline
\end{tabular}

The table shows the percentage of participants within regions choosing a particular answer to each of our questions as well as the number of participants $(N)$ in each region. The last column shows the distribution of answers of all participants. The correct answers are in italics

a This answer is treated as incorrect if the participant states no investment experience

likely to postpone investment decisions. If investment experience is related to the ability to avoid investment mistakes, we expect that wealth and income will be related to investment competence. Homeowners may have a different investment attitude than non-homeowners, seeing as they are more likely to have experience with financial decisions related to mortgages. Additionally, we control for influences driven by job position.

As demographic controls we include age, gender, education, and household size. We expect that older and male respondents will have more investment experience, and that better-educated respondents are likely to have stronger cognitive abilities that help them avoid investment mistakes. Calvet et al. (2009) find that larger households exhibit significantly higher financial sophistication, measured as the ability to avoid mistakes such as under-diversification, inertia in risk taking, and the disposition effect.

In addition to income and wealth, which are used in previous studies as proxies of investment experience, we asked participants to state their investment experience 
with different asset classes on a four-level scale. ${ }^{3}$ In the context of investment competence, this subjective measure could also serve as a control for regional differences in overconfidence.

Finally, we expect that the Swiss might make different investment decisions due to their strong exposure to the banking industry, that is, they are probably more likely to be employed in the financial sector or may have an easier access to advisors than the non-Swiss. If employment in the banking industry matters for investment competence, we expect that it will be reflected in the participants' investment experience. Regarding the availability of financial advisors, we expect that easier access to advisors does not necessarily improve decisions. A necessary condition for learning from advisors is that the advisor's opinion is actually considered when making decisions. To assess individual willingness to improve the quality of decision-making with the help of an advisor, we asked participants to state how important they think an advisor's opinion (their own advisor or a potential advisor) is in making their financial decisions.

\subsection{Descriptive statistics}

The results of this study are based on the answers of 2039 individuals. About half of them live in Switzerland and the rest live in the neighboring regions of Germany, Italy, and France. Thirty-five percent of all participants live in the German-speaking part of Switzerland, $10 \%$ in the French-speaking part, and $5 \%$ in the Italian-speaking part. The sample distribution corresponds to the language distribution in the Swiss population. In the sample outside of Switzerland, $18 \%$ of all participants live in the southern part of Germany, $15 \%$ in the north regions of France, and $18 \%$ in the north regions of Italy.

Table 2 summarizes the characteristics of the regional samples. The sample is well balanced. Forty-nine percent of the respondents are female. All age groups are well represented, and the sample's age structure is comparable to the age structure of permanent residents of Switzerland. According to the Swiss Federal Statistical Office, the distribution of permanent residents of Switzerland across the five age classes is $12,22,26,21$, and $17 \%$ (as of 2011). The distribution of our Swiss sample is 7, 22, 30,22 , and $19 \%$.

It is unlikely that it is mainly low-income households that participated in our study. At least in Switzerland, our participants stated higher household income than participants in larger surveys such as the Swiss Labor Force Survey. ${ }^{4}$ In the latter, the distribution of income over the first three income classes is 33, 42, and $15 \%$, with $8 \%$ making no statement about their income (in 2011). The corresponding distribution of income in our Swiss sample is 9, 43, and $30 \%$, with $3 \%$ making no statement.

\footnotetext{
3 Principal component analysis indicates that investment experience is generally not limited to a particular asset class, and experience with different asset classes can be well summarized with one measure.

${ }^{4}$ The Swiss Labor Force Survey is based on statements from about 4000 participants with permanent residence in Switzerland.
} 


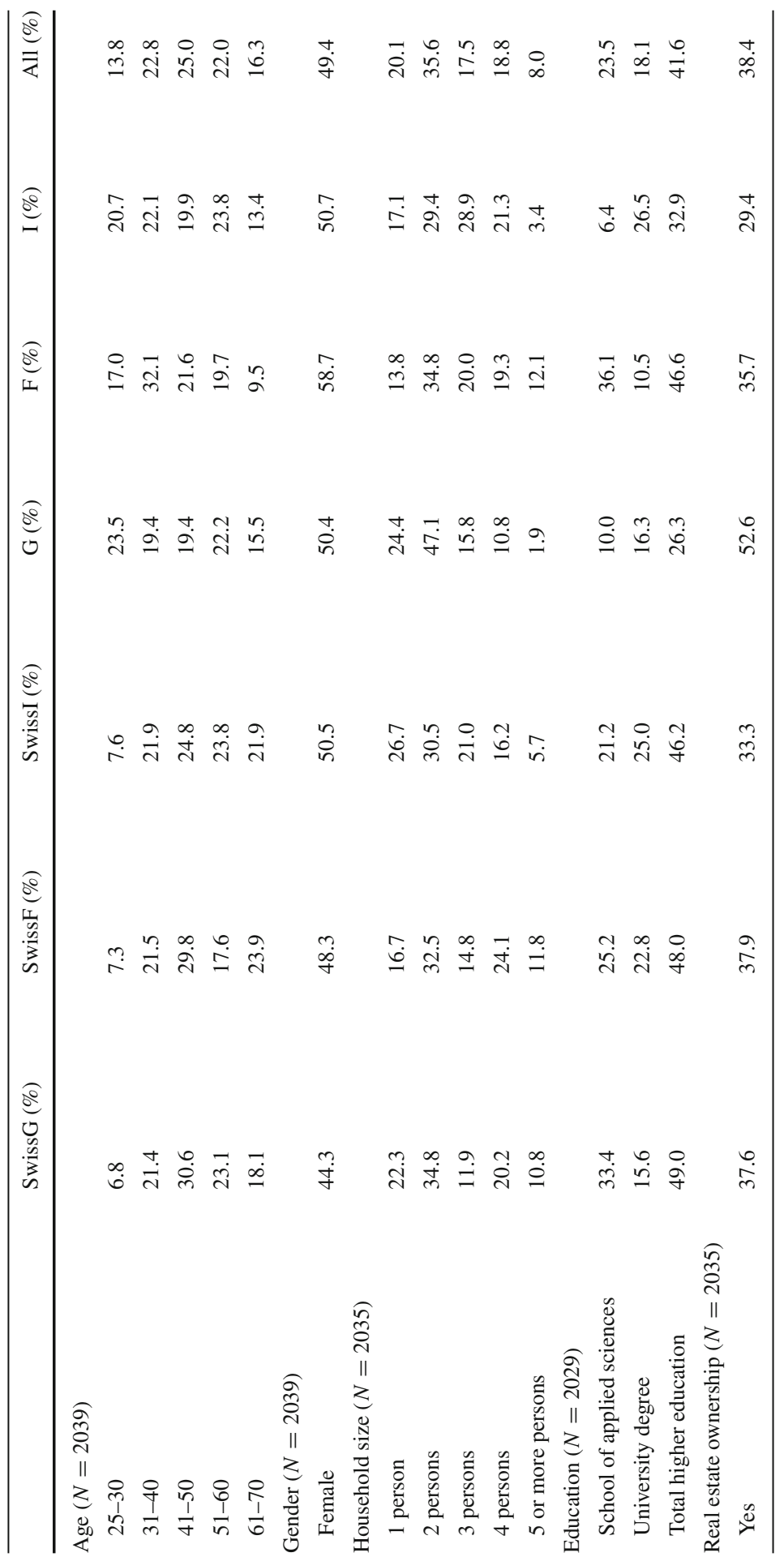




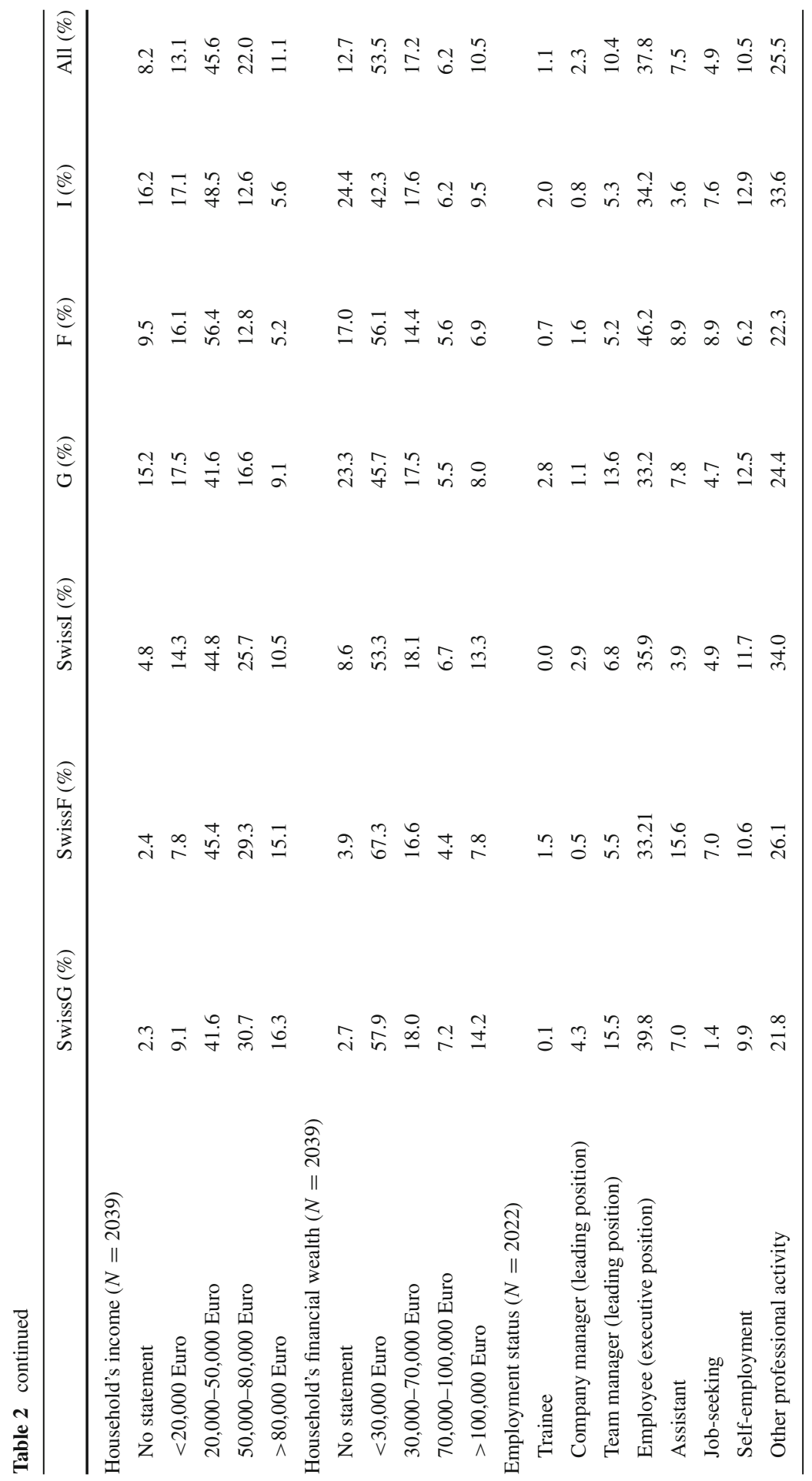




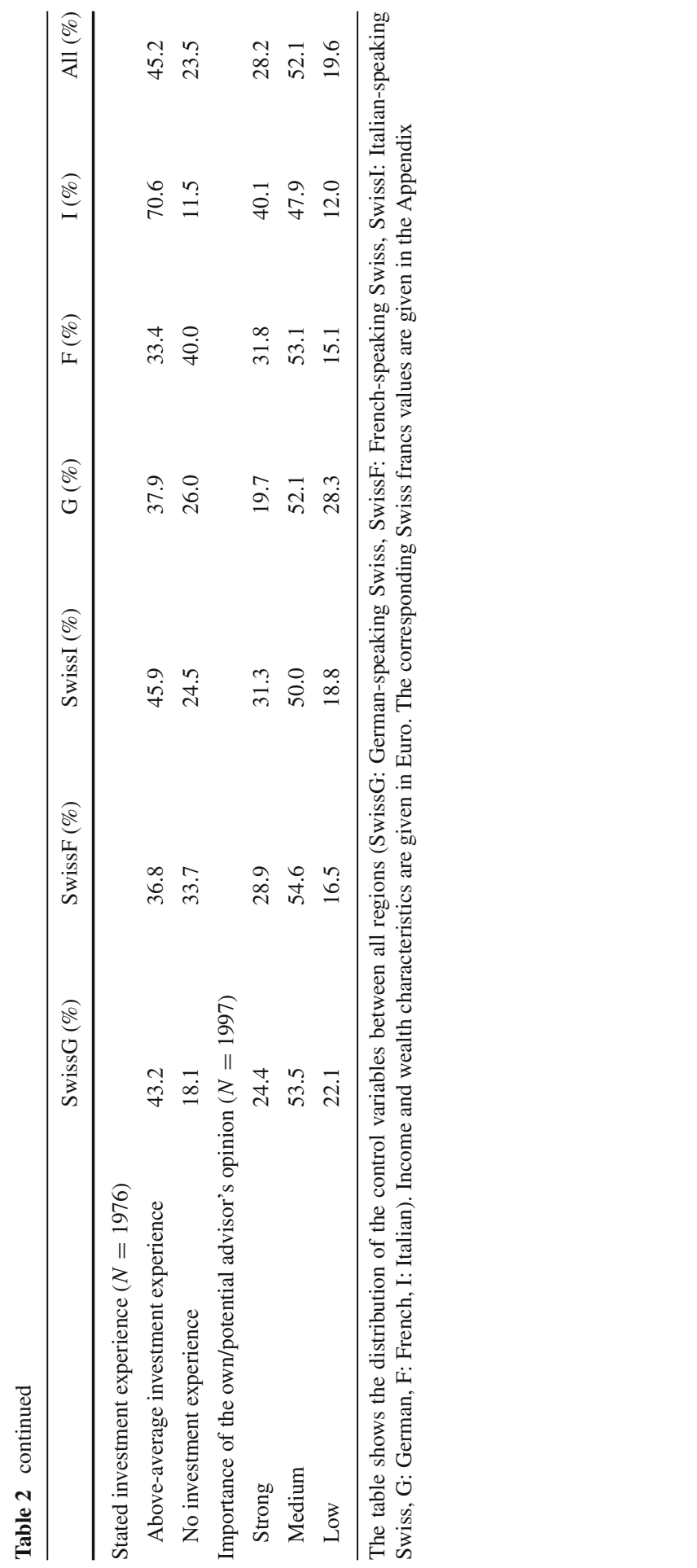


The financial wealth of half the respondents is less than 30,000 Euro. The wealth distribution of the Swiss participants corresponds to the distribution of net wealth according to tax statements of Swiss citizens available from the Swiss Federal Statistic Office. ${ }^{5}$ For the wealth classes used in our survey, the distribution of net wealth as found by the Swill Federal Statistic Office is 66, 10, 13, and $11 \%$, which is comparable to the distribution in our sample of $60,18,7$, and $12 \%$, with $3 \%$ providing no answer (as of 2011).

It is also unlikely that it was mainly low-educated individuals who participated in our survey. According to the Swiss Federal Statistical Office, $35 \%$ of all individuals between 25 and 64 years with permanent residence in Switzerland had a university degree or a degree from a school of applied sciences (in 2011). ${ }^{6}$ In our sample, $49 \%$ of all Swiss participants state that they have one of these higher education degrees.

\subsection{Data analysis}

To compare regional differences in investment decision behavior and competence while taking into account regional characteristics that might influence the results, we use multinomial, ordered, logistic, or robust regressions, depending on the type of the dependent variable. Six indicator variables capture the different regions. As we need to compare regions among each other, we first calculate the predicted values of the dependent variable if all participants lived in one of the six regions keeping everything else equal. Then, we calculate the difference in the predicted values of the dependent variable between two regions of interest, that is, between regions using the same language (SwissG and G, SwissF and F, and Swiss I and I) and between regions using a different language in the same country (SwissF and SwissG, SwissI and SwissG, and Swiss I and SwissF). The statistical significance of these differences is tested with the Delta method. All tests are adjusted for multiple comparisons by the Bonferroni method. We will conclude that there is Swissness if the differences in the predicted values of the dependent variable between Swiss and non-Swiss speaking the same language are larger (in absolute terms) than the differences among Swiss speaking different languages. In the first part of the analysis, the dependent variable is the estimated probability for a particular answer. In the second part of the analysis, the dependent variable is the number of investment mistakes, which we use as a proxy for investment competence.

\section{Results}

\subsection{Differences in investment decision behavior}

We estimate multinomial logistic regressions with the answers to a particular question as a dependent variable. Table 3 includes the estimated differences in the predicted

\footnotetext{
5 Source: http://www.bfs.admin.ch/bfs/portal/de/index/themen/20/02/blank/key/vermoegen.html.

${ }^{6}$ Source: http://www.bfs.admin.ch/bfs/portal/de/index/themen/15/17/blank/01.indicator.406101.4086.ht $\mathrm{ml}$ ?open=9\\#9.
} 
probabilities between two regions of interest. For convenience, the dependent variables for each regression are included in the table's left-hand column. The independent variables are set out across the top of the table. For brevity, we do not report estimation results for the control variables. For each question, we test whether the differences between the answers are statistically significant. We find that only in the second survey questions can the answers (a) to (d) be pooled. For all questions, HausmanMcFadden tests suggest that the null hypothesis of independent alternatives cannot be rejected.

Columns 1-3 of Table 3 show the estimated differences in the decision behavior of Swiss and non-Swiss speaking the same language. The results in columns 4-6 show the estimated differences in the decision behavior of Swiss speaking different languages. The results suggest that Swiss decide differently than their closest neighbors abroad who speak the same language, while the differences among Swiss speaking different languages are, for most questions, insignificant. This observation suggests that Swiss are closer to each other than to their neighbors abroad speaking the same language, that is, there is Swissness in the decision behavior.

While there is Swissness in decision behavior for most of the questions, there are two exceptions. The first one is the perceived attractiveness of different asset classes as long-term investments. Although there are no regional differences in the perceived attractiveness of gold, we observe Swissness in the perceived attractiveness of cash and bonds but no Swissness in the perceived attractiveness of real estate, stocks, and alternative investments.

The second exception involves reasons for continuing an investment. Comparing again the differences between Swiss and non-Swiss and the differences between Swiss, we conclude that in the consideration of previous gains and trends, Swiss are closer to their neighbors abroad speaking the same language than to other Swiss. However, we observe strong Swissness in the propensity to admit a lack of experience when answering this question (answer d).

Apart from these two exceptions, we observe no significant differences in the decision behavior of Swiss, but significant differences in the decision behavior of Swiss and non-Swiss speaking the same language. Hence, we conclude that there is Swissness in decision behavior that cannot be explained by regional demographic and socioeconomic differences.

\subsection{Regional differences in investment competence}

To compare regional differences in investment competence, we first evaluate the individual answers with respect to their capacity to motivate investment mistakes, as discussed in Sect. 2.2. To decide which questions should be included in the evaluation of investment competence, we calculate the correlations between the answers and test their statistical significance (see Table 9 in the Appendix). These correlations reflect the internal consistency of the questions. We observe that two questions ("financial planning" and "past short-term risks") show a negative or no significant correlation with all other questions. It seems that these questions measure a different construct 


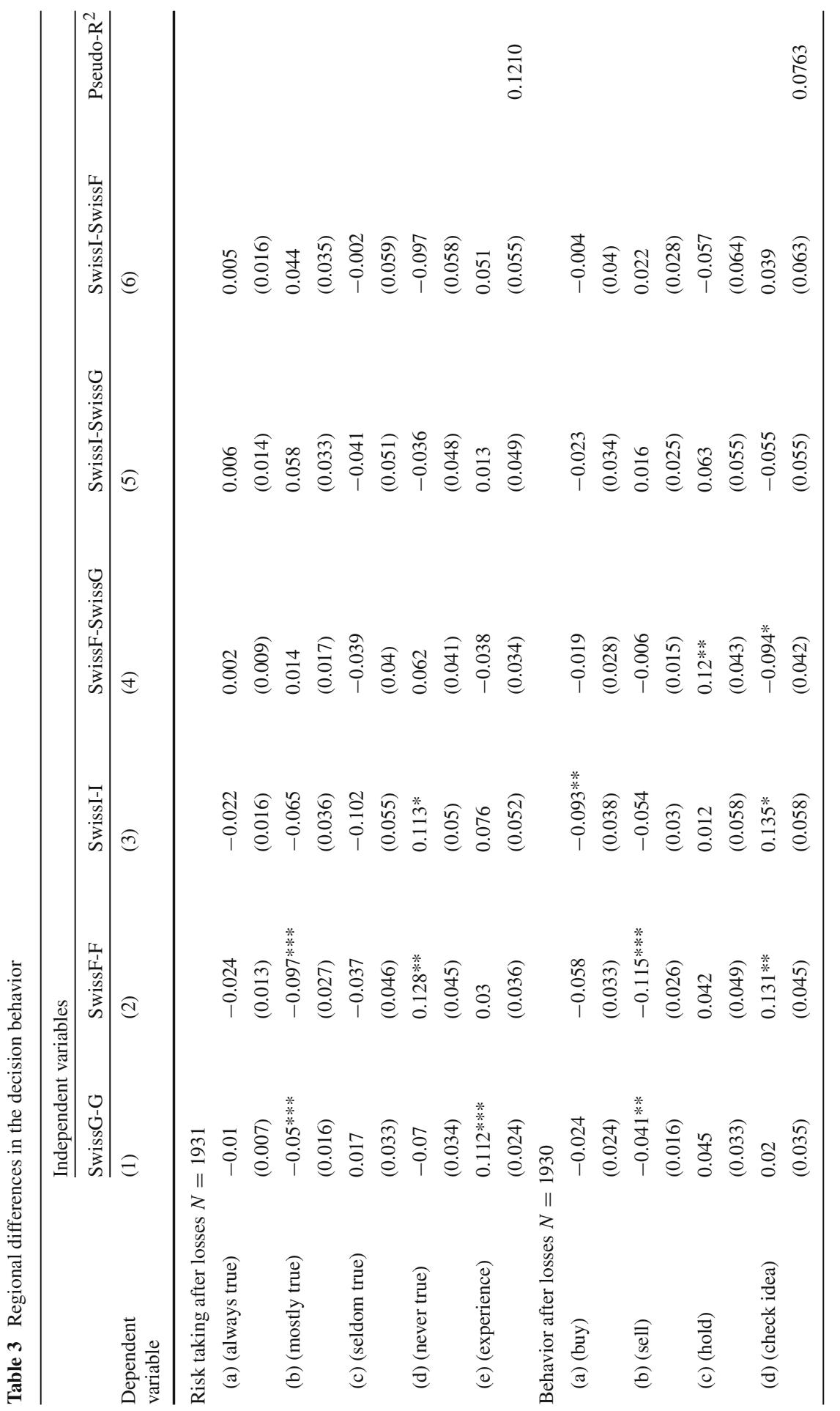




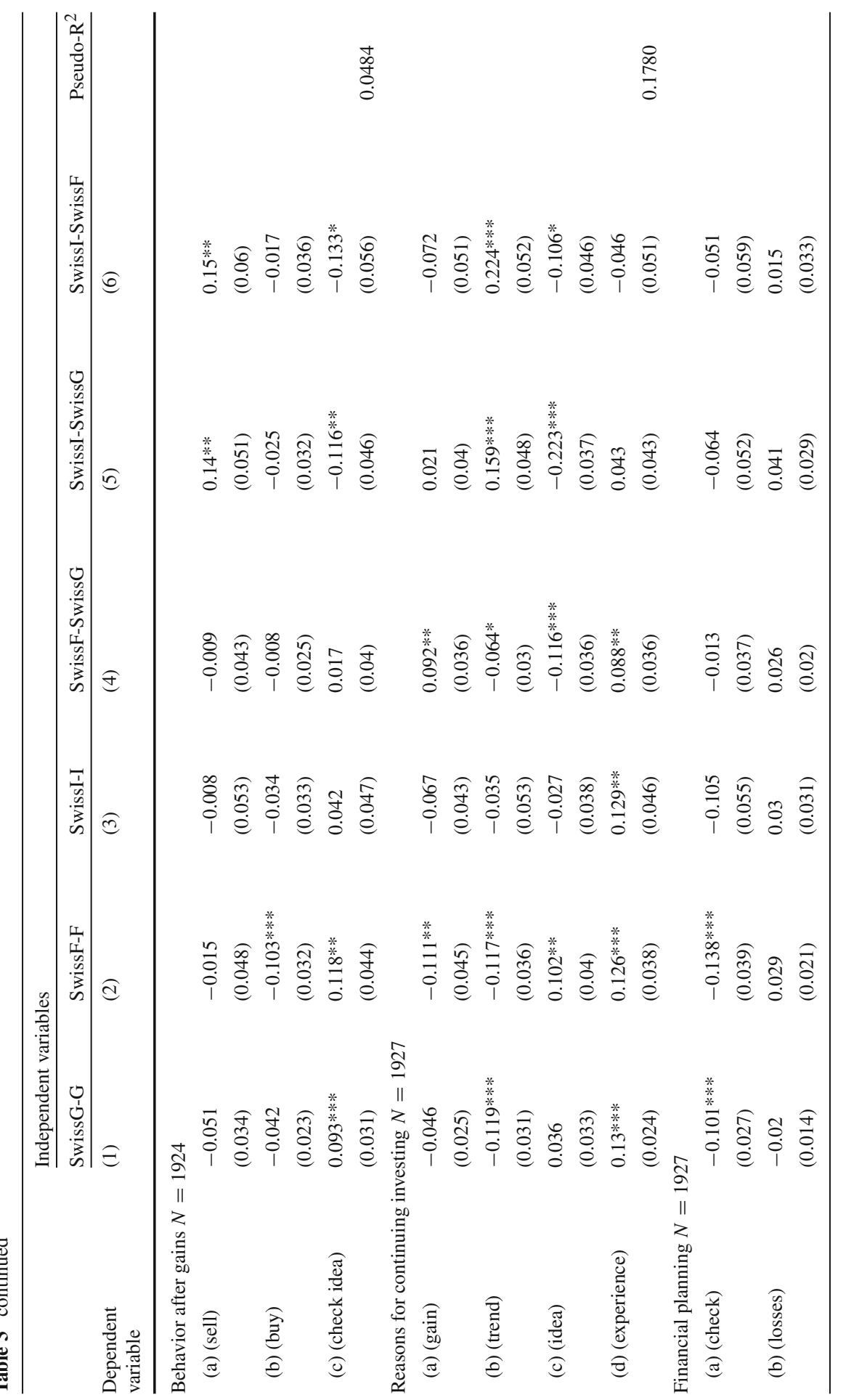




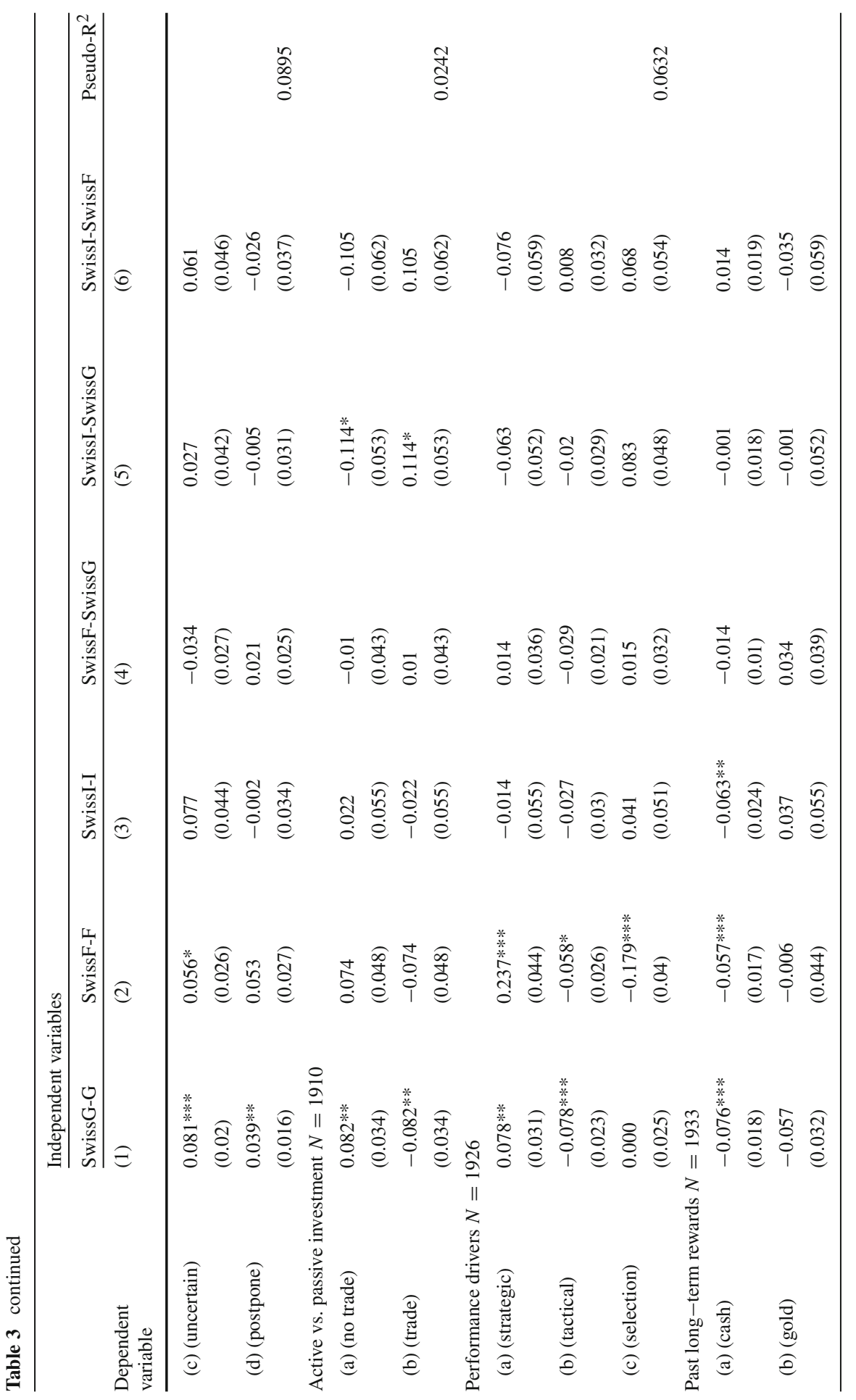




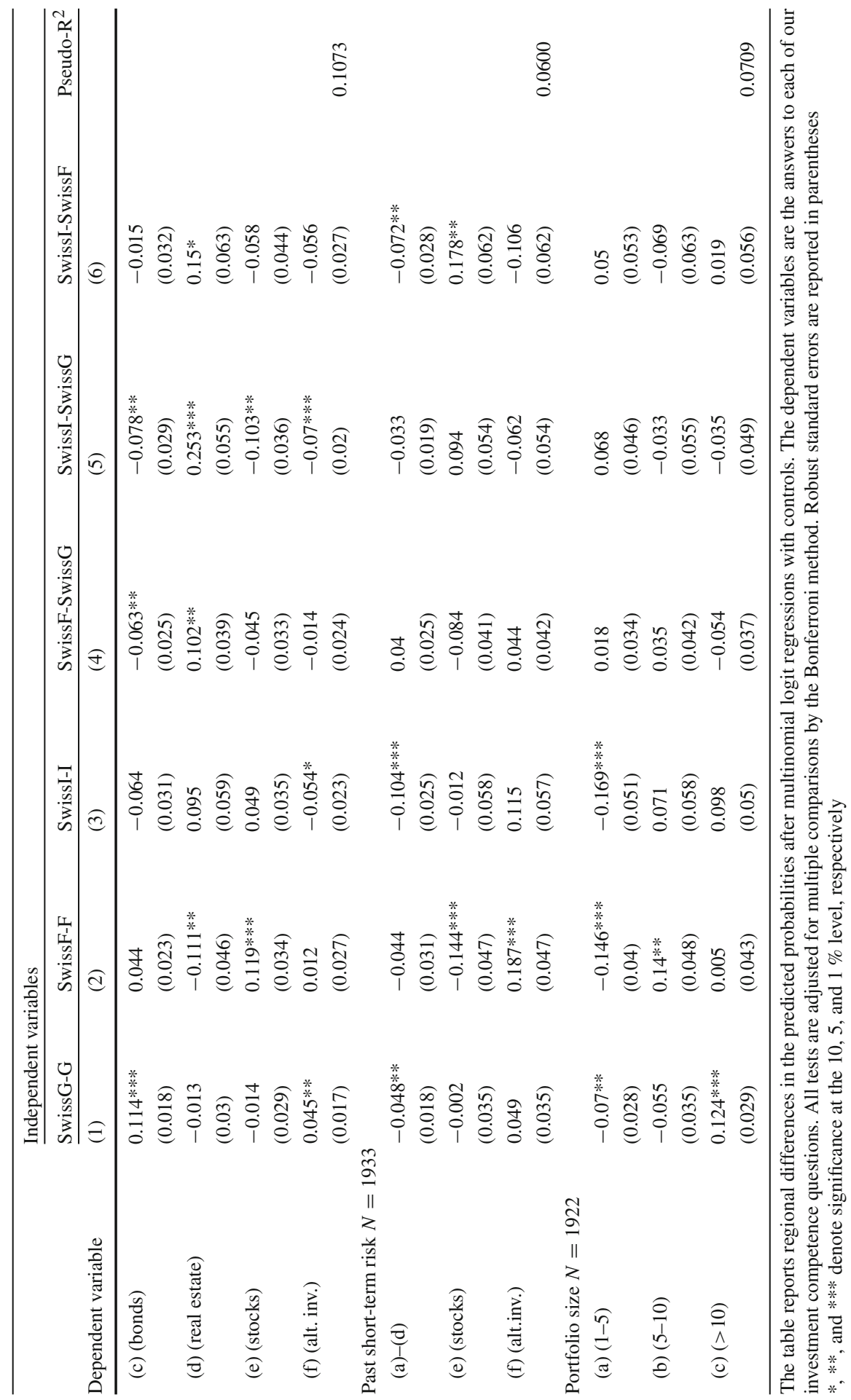


than the rest of the questions. Hence, we remove these questions from the investment competence measure.

Principal component analysis applied on the rest of the questions suggests that the questions can be analyzed in three dimensions. Table 10 in the Appendix shows the loadings of the questions on each of these dimensions. The first dimension includes questions asking for a decision in the context of gains and losses ("risk taking after losses", "behavior after losses", "behavior after gains", "continuing investing"). Since mistakes in answering these questions are chiefly driven by emotional, we call this dimension "emotional competence". The second dimension includes questions assessing investment knowledge ("past rewards", "performance driver", "portfolio size"). We call this dimension "investment knowledge". The third dimension includes the question about "random walk trading". Due to the low correlations between the questions, the three dimensions explain only $53 \%$ of the variance in the data. For this reason, we refrain from using the principal components as proxies for investment competence. Instead, we use the structure suggested by the principal component analysis to build three simple indices of investment competence based on the number of questions answered suboptimally. The indices include missing values only if none of the questions have been answered; otherwise, the indices count the number of mistakes in the questions that were answered.

Table 4 includes summary statistics of the investment competence in each dimension. All Swiss show higher emotional competence and better knowledge than non-Swiss. However, in terms of trading on a random walk, only German- and Frenchspeaking Swiss show greater competence than non-Swiss. In the following, we assess whether the stronger investment competence of Swiss establishes Swissness after considering differences in investment competence driven by the control variables introduced in Sect. 2.3.

Table 5 reports differences in the predicted competence between regions and between individuals with different characteristics. Depending on the dependent variable, we use ordinal logit, logit, or robust regressions using iteratively reweighted least squares. The results suggest that regional differences depend on the type of competence. For emotional competence, Swiss in all regions show a better ability to respond optimally to gains and losses than their neighbors abroad speaking the same language. The largest differences (in the range between 11-14\%) are among participants with lower competence. Additionally, all differences in the emotional competence of Swiss are not statistically significant, leading to the conclusion that there is Swissness in all language regions.

Only German- and French-speaking Swiss have significantly better investment knowledge than their neighbors abroad, with no significant differences among each other. The investment knowledge of Italian-speaking Swiss is similar to the investment knowledge of Italians and much lower than the knowledge of German-speaking Swiss. We conclude that there is Swissness only in the two main language regions of Switzerland. There is no Swissness in the ability to avoid excessive trading.

For all questions, Swiss make significantly lesser mistakes than their neighbors abroad do, but there are significant differences in the investment competence of Italianand German-speaking Swiss. Since the latter differences (0.543) are smaller than the estimated differences between German-speaking Swiss and German (0.611), we 


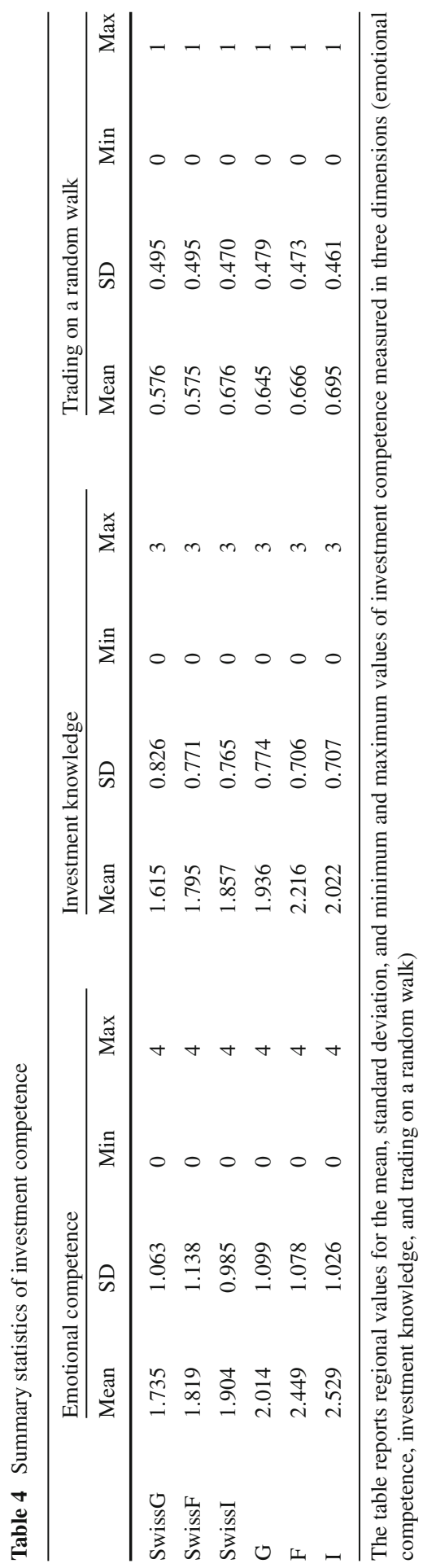




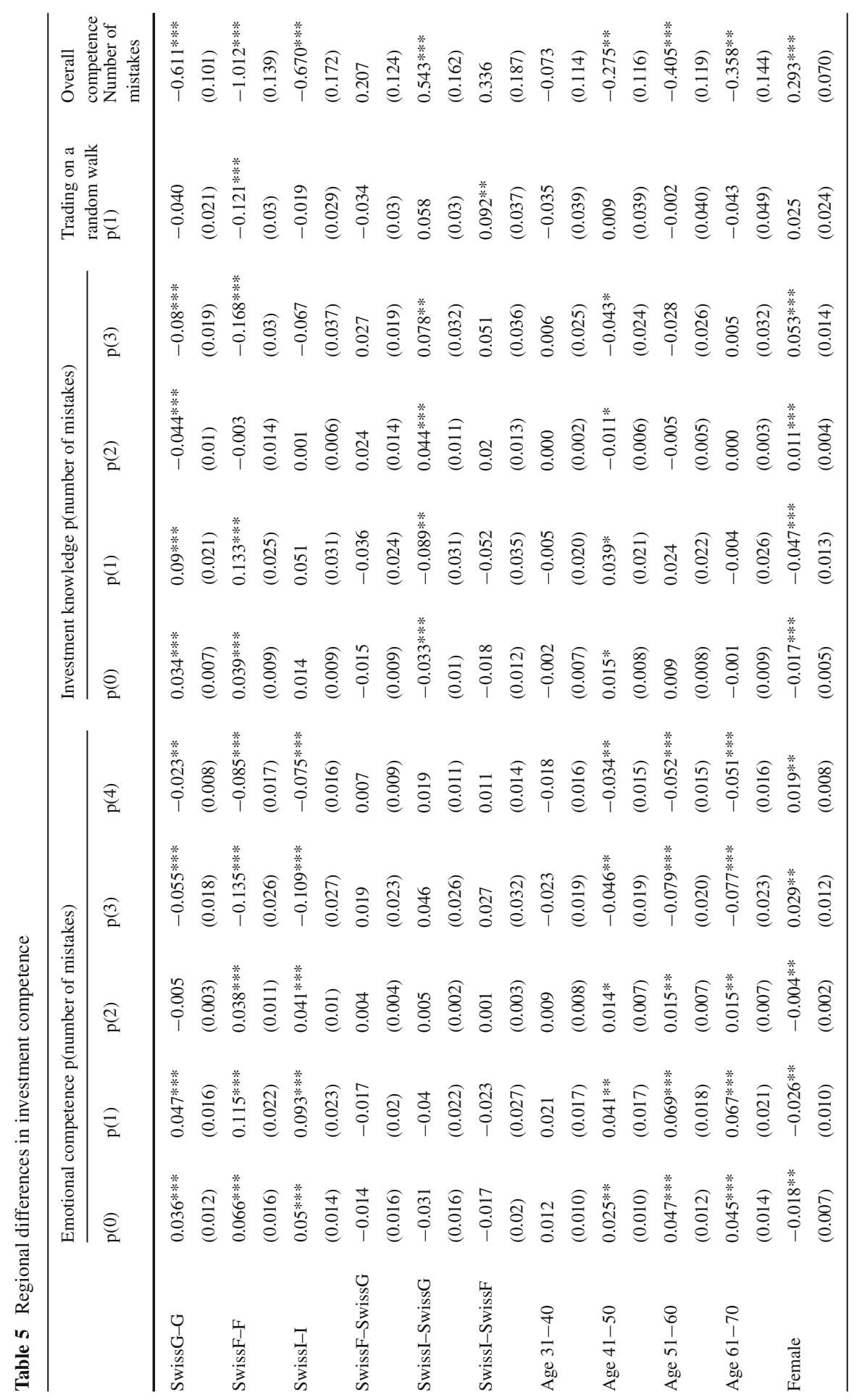




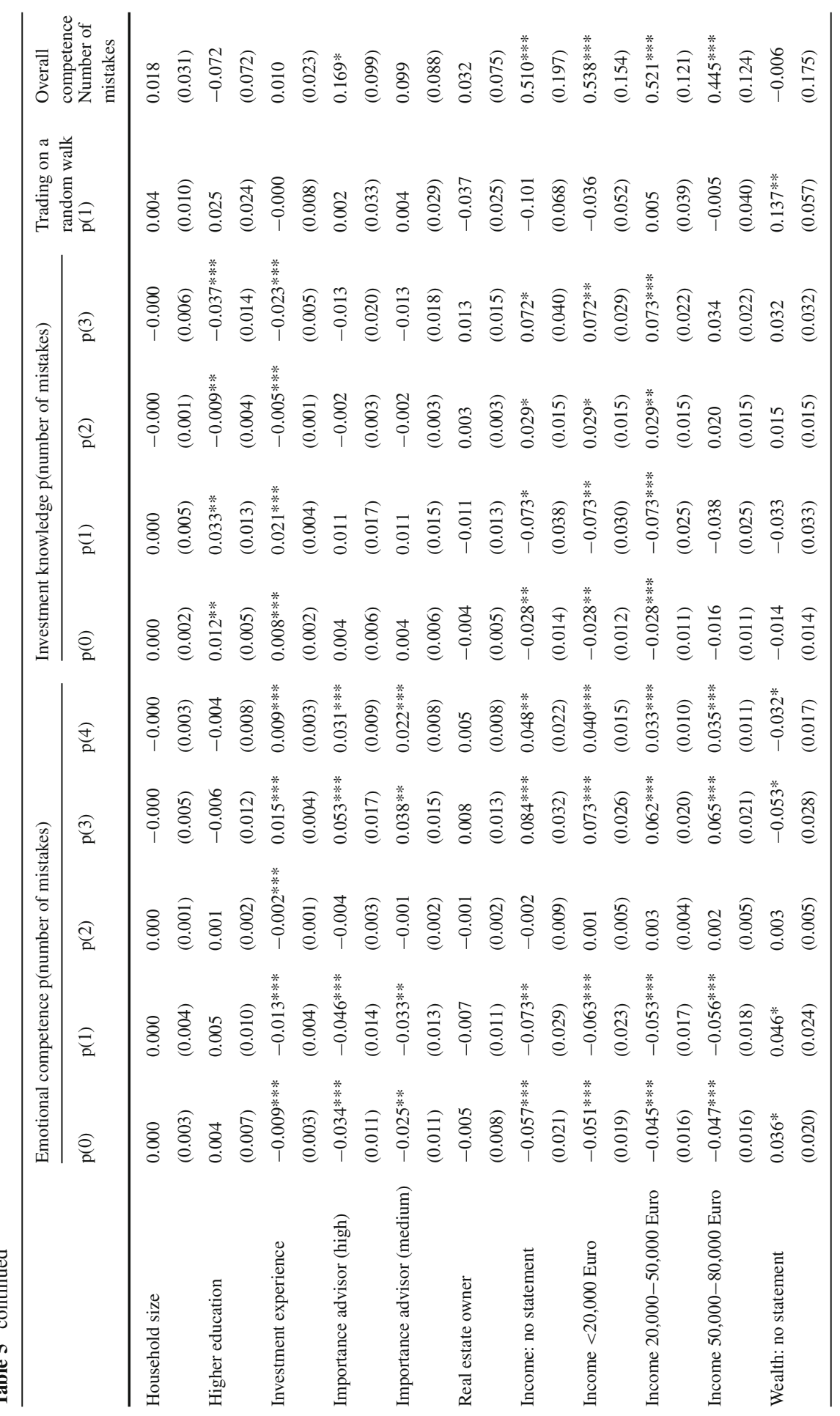




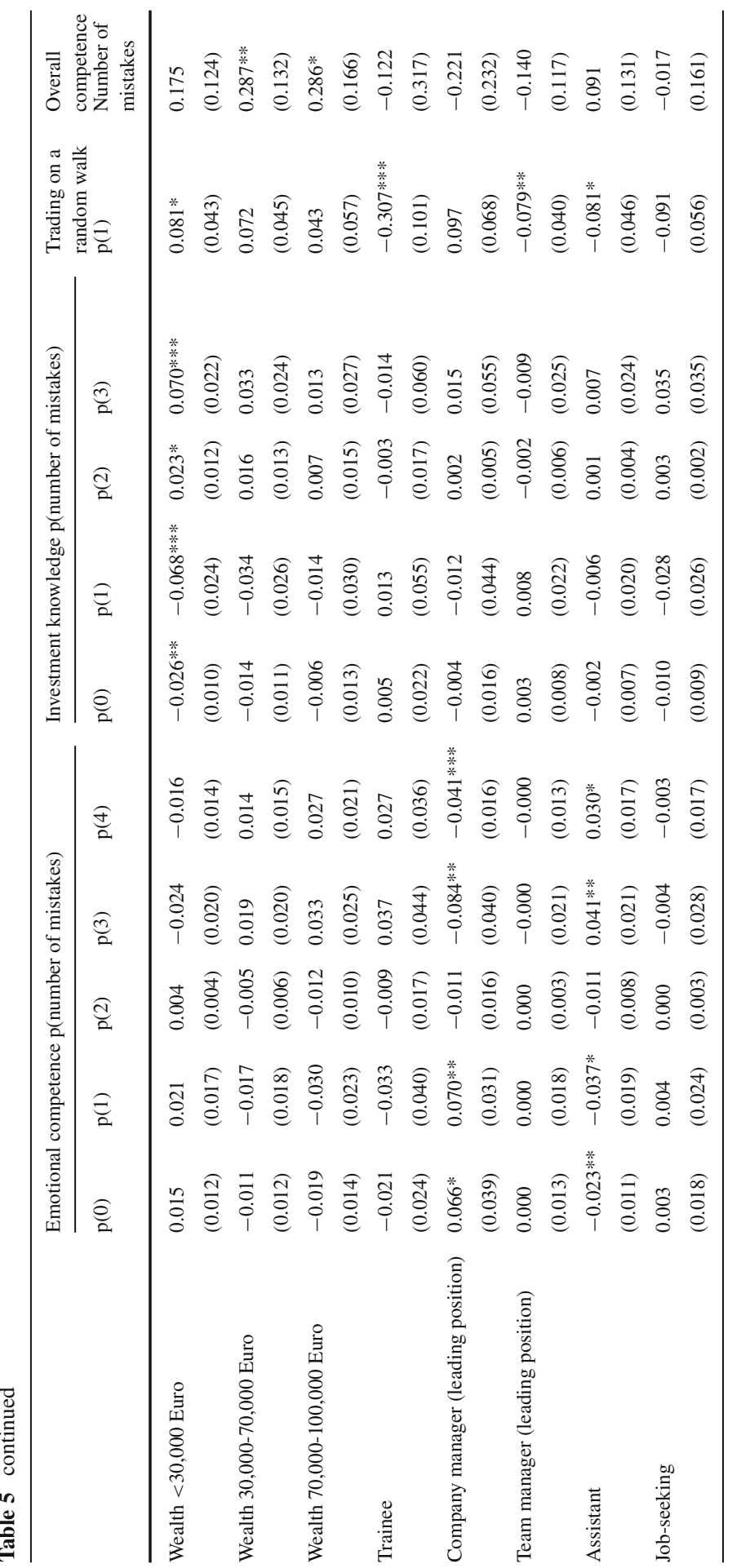




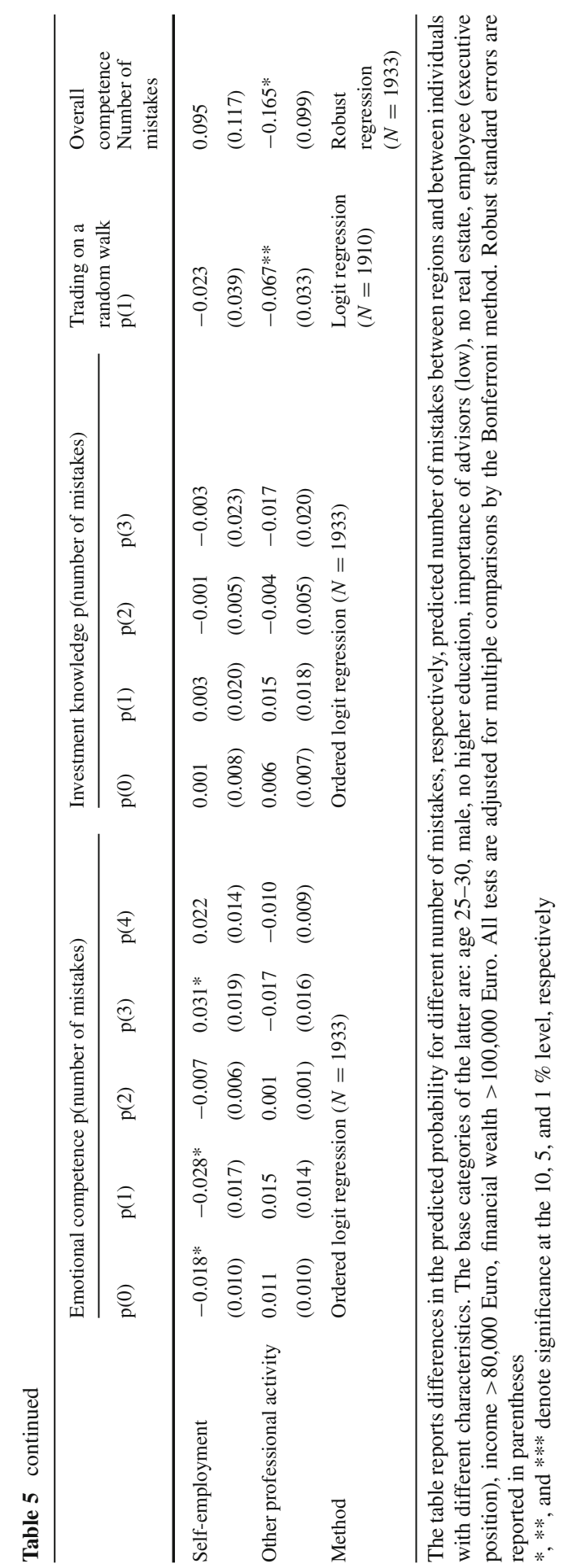


conclude that there is Swissness in overall investment competence. In the context of the previous results, we can say that the Swissness in investment competence is more likely to be emotionally than knowledge driven.

Beyond regional differences, we find that individuals with more investment experience also have more investment knowledge. However, these individuals are significantly more likely to respond emotionally after gains and losses. Similarly, individuals with higher education exhibit more knowledge, but their decisions are affected by the same emotions as the decisions of individuals with less education. Emotionally driven mistakes are less likely for older, male participants with high income in leading job positions who do not consider an advisor's opinion important. Financial knowledge is stronger for male participants with high income and high wealth. Overall investment competence increases with age, income, and wealth. There are significant gender differences in investment competence.

\subsection{Other results}

To shed some light on the drivers of the Swissness effect, we build subsamples based on individual characteristics that could explain the stronger investment competence of Swiss. We hypothesize that Swiss may have a different relationship with their advisors than non-Swiss and that this may influence their ability to learn from advisors. Table 6 reports regional differences in emotional competence and in investment knowledge for three subsamples sorted by stated importance of advisor's opinion. The degree of Swissness varies between the subsamples. For emotional competence, the degree of Swissness increases with the importance of the advisor's opinion. For investment knowledge, there is Swissness in the subsample of individuals who consider the advisor's opinion of average importance and no Swissness in the other two subsamples. These observations suggest that Swiss are likely to have a different relationship with advisors than non-Swiss that helps them reduce the risk of emotional decisions in the face of gains and losses and improves their investment knowledge.

Another possible reason for the observed Swissness is that Swiss learn from experience in a different way than do non-Swiss. To test this conjecture, we evaluate regional differences in two subsamples defined according to the average investment experience in the whole sample. Table 7 reports the estimated regional differences in emotional competence and investment knowledge between individuals with above-average investment experience and individuals with below-average investment experience. The degree of Swissness is similar in both subsamples, indicating that the Swissness is unlikely driven by regional differences in ability to learn from experience.

The results on the drivers of overall investment competence are reported in Table 8. The results suggest that the degree of Swissness increases with the stated importance of an advisor's opinion and it decreases with investment experience. Swissness is strongest in the subsample of individuals with below-average investment experience and in the subsample of individuals who consider the advisor's opinion very important. It seems that Swiss are not better at learning from experience, but they are better than their neighbors abroad at learning from advisors. 


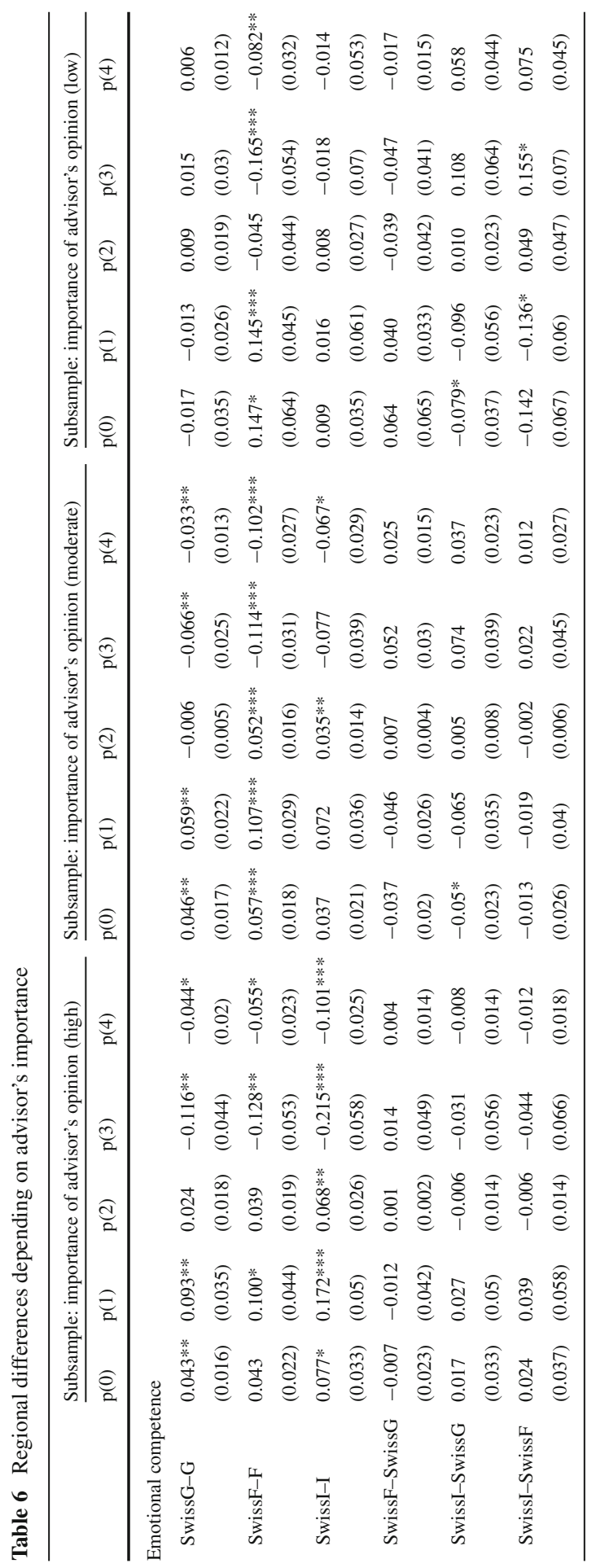




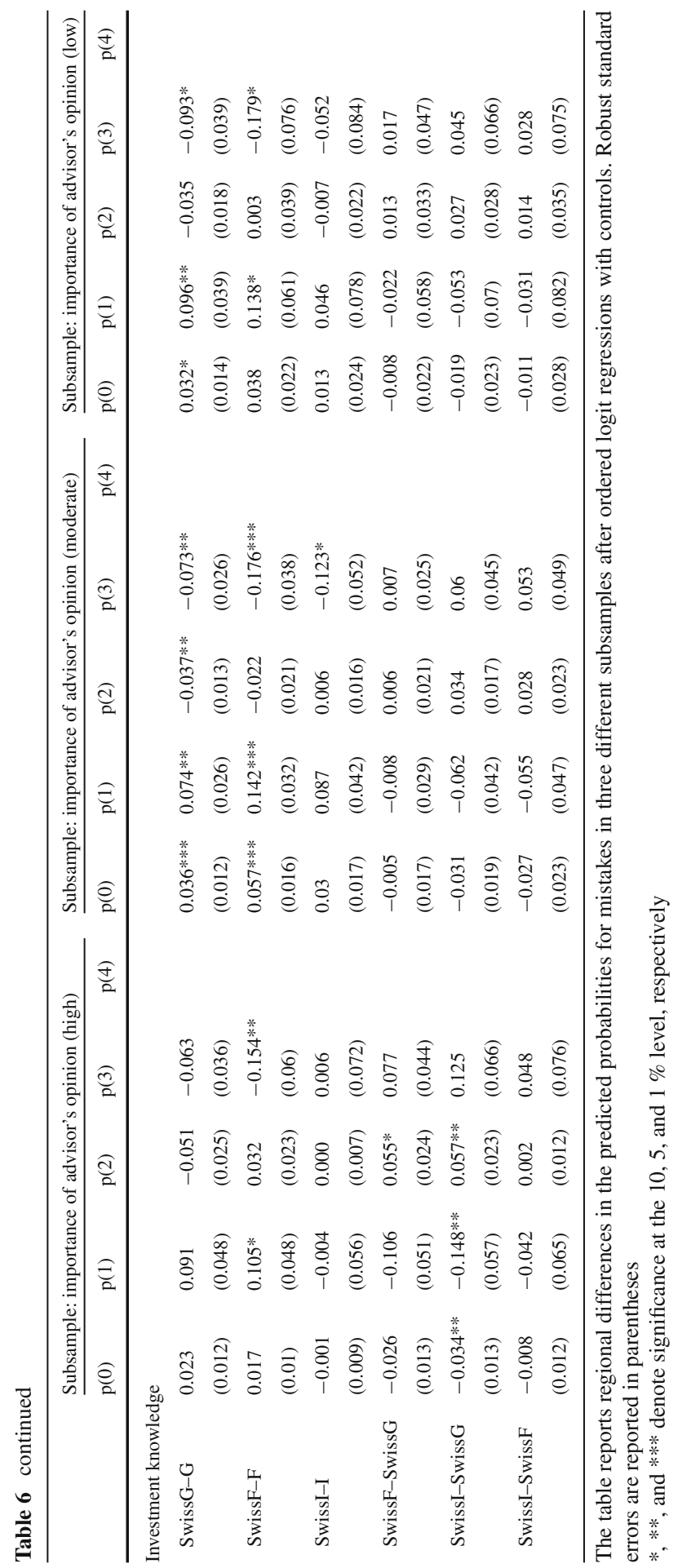




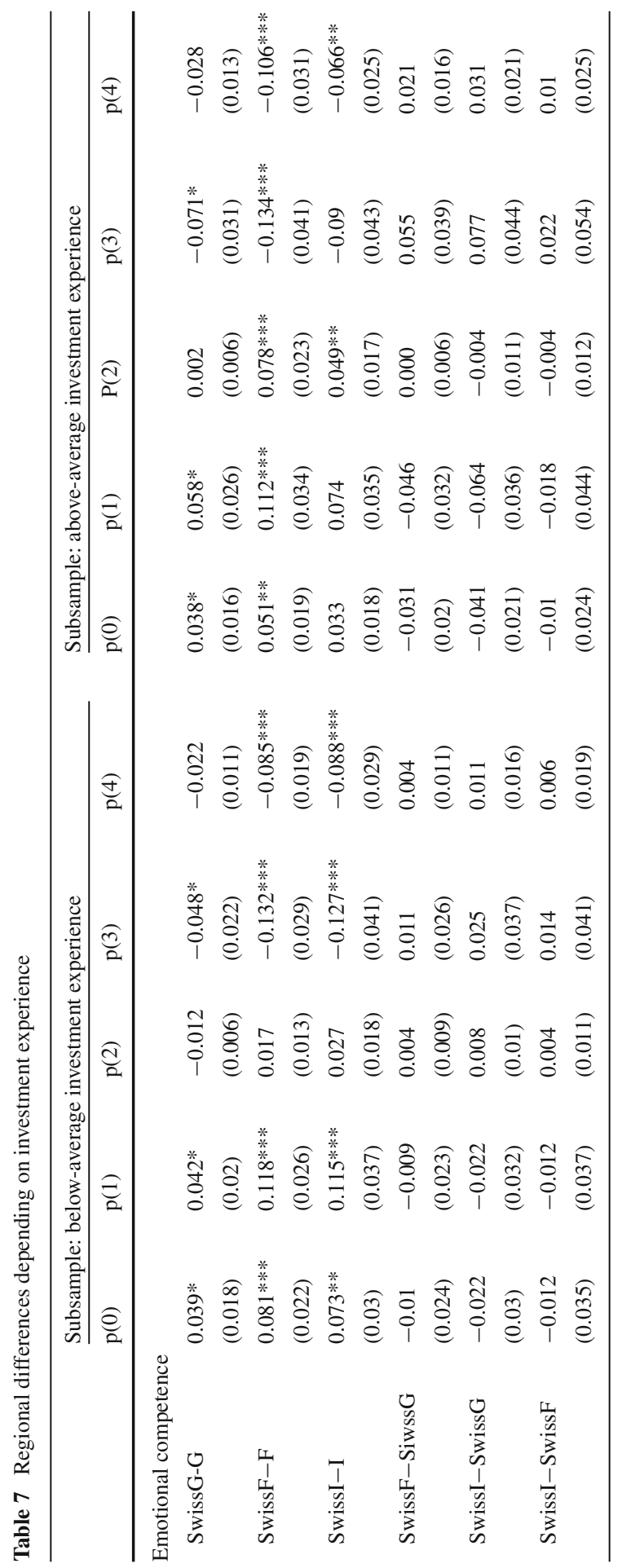




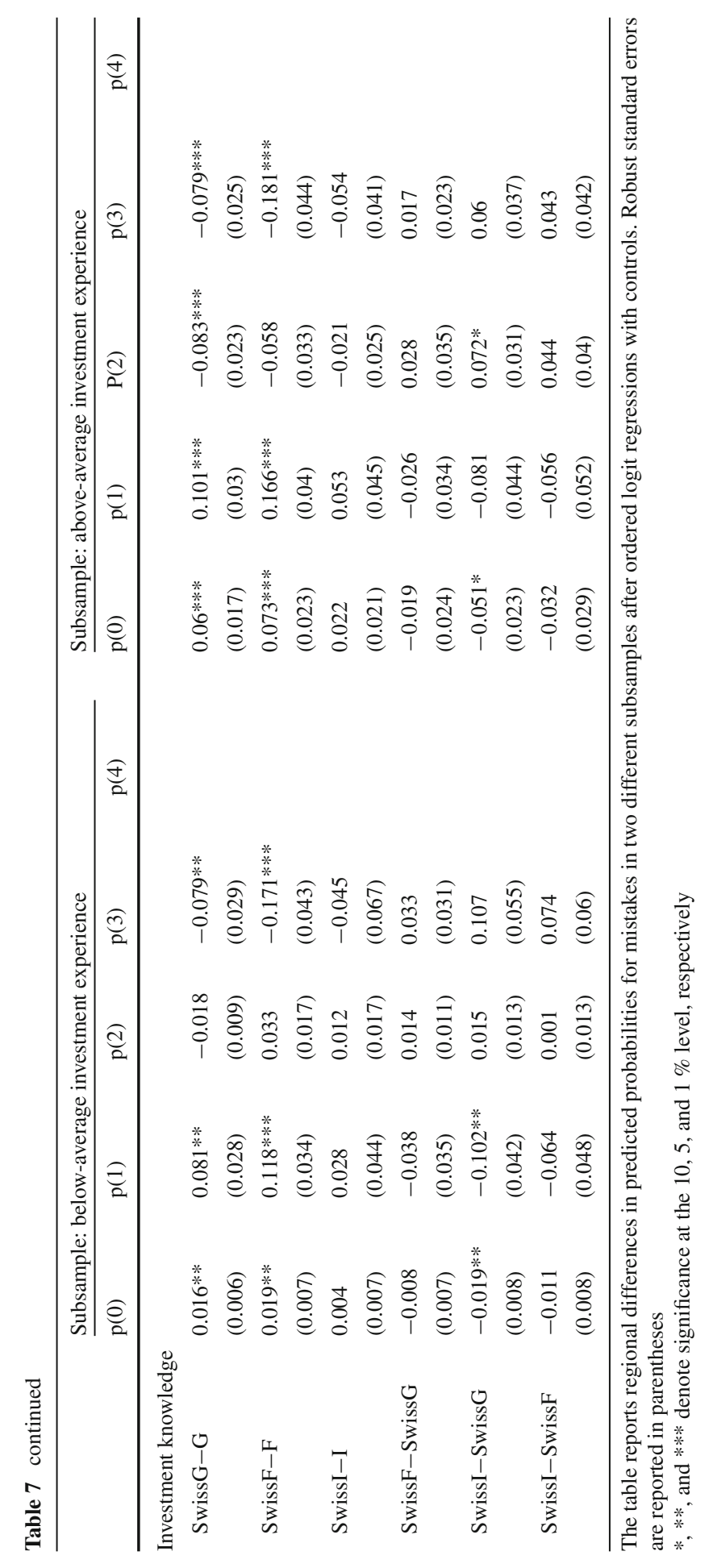




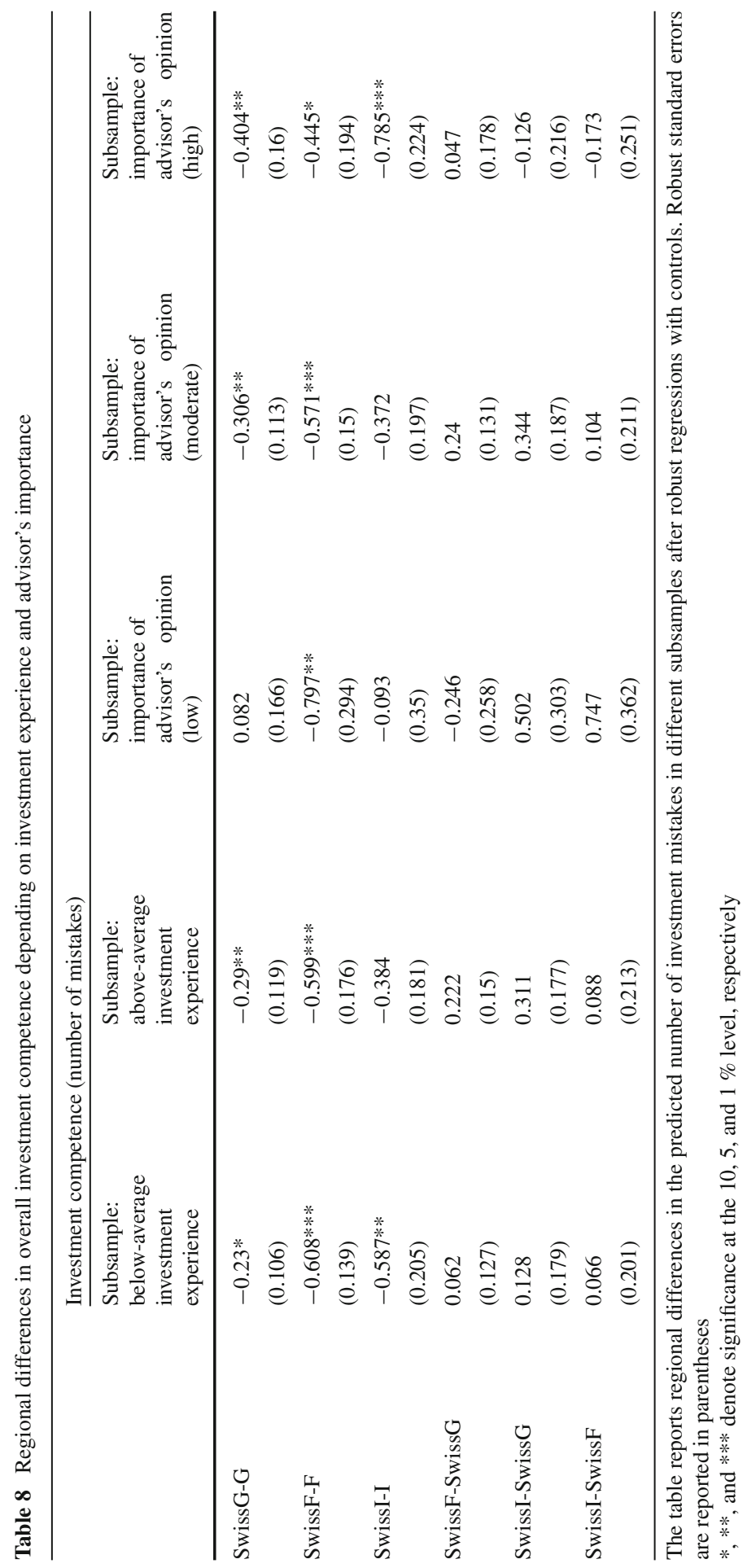


A disadvantage of a measure of investment competence based on the number of incorrectly answered questions is that the latter are weighted equally. However, there is considerable variation in the percentage of respondents answering the questions suboptimally, as Table 1 shows. Since these differences may reflect difficulty in understanding the question rather than lack of competence, we use different weights for each question as an alternative. The procedure is very similar to the weighting method PRIDIT used by Behrman et al. (2012) to create more robust financial literacy scores.

To decide the weights of each question, we refer to the percentage of respondents answering the question in a biased way. Mistakes in answering questions with a higher error rate ("difficult" questions) receive a lower weight than mistakes in answering questions that most respondents answered correctly ("easy" questions). For example, the first question can be considered "difficult" as $82 \%$ of all respondents answer it suboptimally. Mistakes in answering this question receive a weight of 0.18 . In contrast, mistakes in answering the question on financial planning receive a weight of 0.82 as only $12 \%$ of all respondents answered this question suboptimally. For the assessment of investment competence, the weighting mechanism gives a credit for avoiding mistakes in "difficult" questions and applies a penalty for suboptimal answers to "easy" questions. The weights are multiplied by -1 to create a scale that increases with competence.

An examination of the summary statistics of the weighted scale (see Table 11 in the Appendix) confirms our previous observations. The regression analysis with the weighted scale reported in Table 12 in the Appendix shows that our qualitative results remain robust, that is, we observe Swissness in emotional competence and partial Swissness in investment knowledge. The Swissness effect in overall investment competence is even stronger than in the basic case using an unweighted scale. The impact of the control variables on investment competence remains robust as well.

Finally, we test whether the exclusion of the internally inconsistent questions has an impact on the existence of Swissness. Table 13 in the Appendix shows that all Swiss regions remain closer to each other than to their linguistically closest neighbors abroad.

\section{Discussion}

The results of our analysis suggest that although language may be closer to the individual self than the country of residence, there are greater similarities in the decision behavior of Swiss speaking different languages than between Swiss and their linguistically closest neighbors abroad. These similarities are also found for the ability to avoid emotionally driven mistakes and, to some extent, for the ability to avoid mistakes due to lack of investment knowledge. So what are the potential drivers of this kind of Swissness?

Our analysis reveals that the Swissness effect depends on the client-advisor relationship. Swissness in emotional competence increases with reliance on the advisor's opinion. In general, a stronger reliance on the advisor's opinion enhances the ten- 
dency to react emotionally to gains and losses. Perhaps individuals who rely strongly on advisors are basically delegating decision-making and thus do not have personal experience from which to learn how to handle the emotional rollercoaster of gains and losses. Our results show that Swiss in all language regions are less likely to avoid such learning opportunities than their neighbors abroad. It seems that there are differences in the client-advisor relationship that help Swiss develop better emotional competence. These differences also affect the transmission of investment knowledge. Greater reliance on an advisor does not necessarily increase investment knowledge. However, we observe Swissness in the investment knowledge of individuals who consider advisor opinions moderately important and no Swissness in the other two subsamples. This suggests that Swiss make a better use of advisors when learning about asset classes and investing than do their neighbors abroad. The regional differences in the client-advisor relationship are probably culturally based.

Switzerland's political system of direct democracy may provide an alternative explanation for the observed Swissness. Feld and Kirchgassner (2000) suggest that the opportunity to decide for oneself on political issues provides an incentive to collect more information and engage in dialogue with others. Political discourse in Switzerland is not restricted to intellectual circles. The Swiss attitude toward information collection could have an impact on the quality of their investment decisions. Kuo et al. (2013) find that if investors are willing to learn about firms in which they invest, they make more rational investment decisions. Hence, if Swiss, as members of a direct democracy, generally demand more information when making investment decisions, they might exhibit better investment competence by avoiding certain investment mistakes.

Regarding the question of who is in most need of help when making investment decisions, we find that education improves investment knowledge, which is in line with the results of Brown and Graf (2013) who study financial literacy of the Swiss. However, we also find that education does not help decision-makers to avoid emotionally driven mistakes. Hence, our results suggest that education can help investors decide on an optimal asset allocation, but it cannot help them deal with the emotional risks of investment. Hence, educational measures should address not only the financial literacy of inexperienced investors, but also their awareness of the risks associated with emotionally based decisions. Regarding the target audience, our results suggest that younger, female individuals with lower income have the greatest learning potential. The importance of income is also found in studies using real investment decisions. For example, Calvet et al. (2009) find that the disposition effect is stronger in the portfolios of Swedish households with lower income. Unfortunately, portfolio mistakes by lower-income households tend to be more serious, as they cannot afford to make them.

Our results also have implications for regulators. If the goal is investor protection, then regulators should not confuse investment experience with competence. Our results suggest that experienced investors are more likely to understand investments risks, but they are also less prepared to face the emotional risks of investing. Empirical results of Koestner et al. (2012) confirm this observation. Decision-makers appear to find it difficult to understand the nature and costs of emotionally driven mistakes, such as the disposition effect, and so they tend not to learn from their mistakes. Hence, allowing 
experienced investors to take greater risks increases the risk of emotional reaction with a consequent negative impact on financial performance.

\section{Conclusion}

In this study, we analyze whether there is Swissness in investment behavior and competence. We define investment competence as the ability to avoid investment mistakes. This ability depends on investment knowledge and on the ability to avoid emotional reactions after gains and losses. We find that after controlling for characteristics with a potential impact on investment competence, the Swiss appear to share some traits that make their decision behavior distinguishable from that of nearby foreigners who speak the same language. Specifically, we find that Swiss in all language regions are significantly less likely to make emotionally driven investment mistakes than their linguistically closest neighbors abroad, while the differences in financial knowledge are significant only for German- and the French-speaking Swiss. We conclude that there is Swissness in emotional investment competence and partial Swissness in investment knowledge. The effect can be partially explained by regional differences in client-advisor relationships. While individuals who rely on advisors are usually less prepared to respond optimally to previous gains and losses, we find that the Swiss are less affected and, as a consequence, better prepared to deal with emotions associated with previous gains and losses.

We find that investment experience can be a reliable proxy for investment knowledge. More experienced investors better understand financial risks, but they are also less prepared to cope with the emotional risks of investing. Similarly, education helps improve the investment knowledge, but has limited power to help investors deal with emotions when investing. Hence, measures aimed at protecting investors should not assume that education and investment experience help investors become better investors as successful investing depends not only on knowledge, but also on the ability to deal with emotions.

\section{Appendix}

\section{A. Variable specifications}

Financial income is the household's net disposable income. We use the following equivalents:

- $\leq 20,000$ Euro and $\leq 50,000$ Swiss franks

- 20,000-50,000 Euro and 50,000-100,000 Swiss franks

- 50,000-80,000 Euro and 100,000-150,000 Swiss franks

- $\geq 80,000$ Euro and 150,000 Swiss franks.

Financial wealth is the household's net disposable wealth (without real estate) (e.g., cash, financial assets such as equities, bonds, funds, and pension savings such as $3 \mathrm{a}$ saving accounts used in Switzerland). We use the following equivalents:

- $\leq 30,000$ Euro and $\leq 100,000$ Swiss franks 
- 30,000-70,000 Euro and 100,000-200,000 Swiss franks

- 70,000-100,000 Euro and 200,000-300,000 Swiss franks

- $\geq 100,000$ Euro and 300,000 Swiss franks.

\section{B. Further tests}




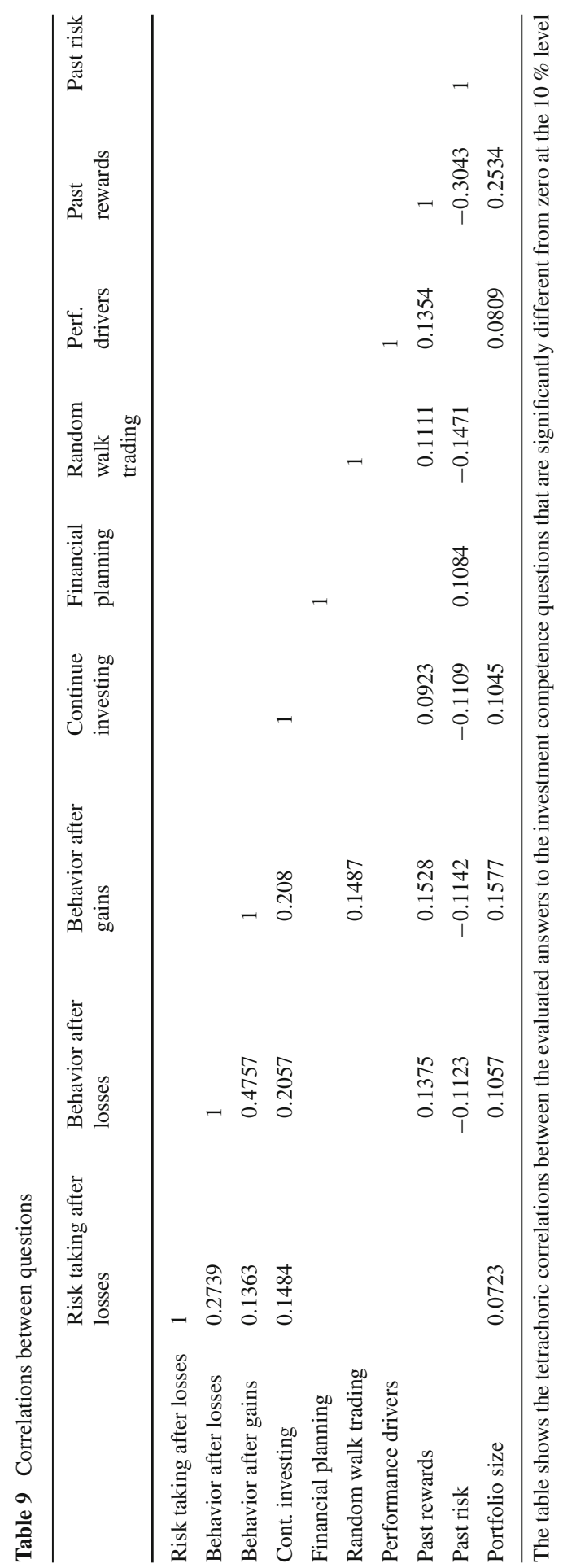


Table 10 Factor loadings after varimax rotation

\begin{tabular}{|c|c|c|c|c|}
\hline & Comp. 1 & Comp. 2 & Comp. 3 & $\begin{array}{l}\text { Unexplained } \\
\text { variance }\end{array}$ \\
\hline Risk taking after losses & 0.451 & & & 0.564 \\
\hline Behavior after losses & 0.596 & & & 0.370 \\
\hline Behavior after gains & 0.538 & & & 0.342 \\
\hline Reasons for continuing investing & 0.357 & & & 0.661 \\
\hline Active vs. passive investing & & & 0.775 & 0.316 \\
\hline Performance drivers & & 0.499 & & 0.555 \\
\hline Past long-term rewards & & 0.636 & & 0.369 \\
\hline Portfolio size & & 0.541 & & 0.556 \\
\hline
\end{tabular}

The table includes the factor loadings of three components based on a principal component analysis on the correlation matrix of investment mistakes after a varimax rotation. Factor loadings smaller than 0.3 have been omitted

Table 11 Summary statistics of weighted investment competence scale

\begin{tabular}{|c|c|c|c|c|c|c|c|c|}
\hline & \multicolumn{4}{|c|}{ Emotional competence } & \multicolumn{4}{|c|}{ Investment knowledge } \\
\hline & Mean & SD & Min & Max & Mean & SD & Min & $\operatorname{Max}$ \\
\hline SwissG & -0.710 & 0.493 & -1.940 & 0.000 & -0.452 & 0.336 & -1.121 & 0.000 \\
\hline SwissF & -0.767 & 0.531 & -1.940 & 0.000 & -0.487 & 0.334 & -1.121 & 0.000 \\
\hline SwissI & -0.800 & 0.462 & -1.940 & 0.000 & -0.523 & 0.342 & -1.121 & 0.000 \\
\hline G & -0.837 & 0.539 & -1.940 & 0.000 & -0.573 & 0.358 & -1.121 & 0.000 \\
\hline $\mathrm{F}$ & -1.060 & 0.571 & -1.940 & 0.000 & -0.695 & 0.371 & -1.121 & 0.000 \\
\hline I & -1.063 & 0.521 & -1.940 & 0.000 & -0.561 & 0.344 & -1.121 & 0.000 \\
\hline
\end{tabular}


Table 12 Differences in investment competence based on a weighted scale

\begin{tabular}{|c|c|c|c|}
\hline & $\begin{array}{l}\text { Emotional } \\
\text { competence }\end{array}$ & $\begin{array}{l}\text { Investment } \\
\text { knowledge }\end{array}$ & $\begin{array}{l}\text { Overall investmen } \\
\text { competence }\end{array}$ \\
\hline \multirow[t]{2}{*}{ SwissG-G } & $0.105^{* *}$ & $0.092 * * *$ & $0.185^{* * *}$ \\
\hline & $(0.038)$ & $(0.027)$ & $(0.046)$ \\
\hline \multirow[t]{2}{*}{ SwissF-F } & $0.28 * * *$ & $0.231 * * *$ & $0.492 * * *$ \\
\hline & $(0.053)$ & $(0.038)$ & $(0.064)$ \\
\hline \multirow[t]{2}{*}{ SwissI-I } & $0.212 * * *$ & 0.027 & $0.238 * * *$ \\
\hline & $(0.065)$ & $(0.046)$ & $(0.079)$ \\
\hline \multirow[t]{2}{*}{ SwissF-SwissG } & -0.053 & -0.013 & -0.031 \\
\hline & $(0.047)$ & $(0.033)$ & $(0.057)$ \\
\hline \multirow[t]{2}{*}{ SwissI-SwissG } & -0.090 & -0.077 & -0.150 \\
\hline & $(0.062)$ & $(0.043)$ & $(0.074)$ \\
\hline \multirow[t]{2}{*}{ SwissI-SwissF } & -0.037 & -0.063 & -0.119 \\
\hline & $(0.071)$ & $(0.05)$ & $(0.086)$ \\
\hline \multirow[t]{2}{*}{ Age $31-40$} & 0.039 & -0.009 & 0.023 \\
\hline & $(0.043)$ & $(0.031)$ & $(0.052)$ \\
\hline \multirow[t]{2}{*}{ Age $41-50$} & $0.101 * *$ & 0.037 & $0.139 * * *$ \\
\hline & $(0.044)$ & $(0.032)$ & $(0.053)$ \\
\hline \multirow[t]{2}{*}{ Age $51-60$} & $0.160 * * *$ & 0.029 & $0.177 * * *$ \\
\hline & $(0.045)$ & $(0.032)$ & $(0.055)$ \\
\hline \multirow[t]{2}{*}{ Age $61-70$} & $0.172 * * *$ & 0.013 & $0.178 * * *$ \\
\hline & $(0.055)$ & $(0.039)$ & $(0.066)$ \\
\hline \multirow[t]{2}{*}{ Female } & $-0.055^{* *}$ & $-0.040 * *$ & $-0.091 * * *$ \\
\hline & $(0.027)$ & $(0.019)$ & $(0.032)$ \\
\hline \multirow[t]{2}{*}{ Household size } & -0.001 & -0.004 & -0.008 \\
\hline & $(0.012)$ & $(0.008)$ & $(0.014)$ \\
\hline \multirow[t]{2}{*}{ Higher education } & 0.018 & $0.053 * * *$ & $0.067 * *$ \\
\hline & $(0.027)$ & $(0.020)$ & $(0.033)$ \\
\hline \multirow[t]{2}{*}{ Investment experience } & $-0.028 * * *$ & $0.019 * * *$ & -0.005 \\
\hline & $(0.009)$ & $(0.006)$ & $(0.011)$ \\
\hline \multirow[t]{2}{*}{ Importance advisor (strong) } & $-0.113 * * *$ & 0.033 & -0.068 \\
\hline & $(0.038)$ & $(0.027)$ & $(0.045)$ \\
\hline \multirow[t]{2}{*}{ Importance advisor (medium) } & $-0.099 * * *$ & 0.014 & $-0.085^{* *}$ \\
\hline & $(0.034)$ & $(0.024)$ & $(0.040)$ \\
\hline \multirow[t]{2}{*}{ Real estate owner } & -0.011 & -0.008 & -0.021 \\
\hline & $(0.029)$ & $(0.020)$ & $(0.034)$ \\
\hline \multirow[t]{2}{*}{ Income: no statement } & $-0.155^{* *}$ & -0.053 & $-0.225^{* *}$ \\
\hline & $(0.075)$ & $(0.054)$ & $(0.090)$ \\
\hline \multirow[t]{2}{*}{ Income $<20,000$ Euro } & $-0.149 * *$ & $-0.088 * *$ & $-0.259 * * *$ \\
\hline & $(0.059)$ & $(0.042)$ & $(0.070)$ \\
\hline
\end{tabular}


Table 12 continued

\begin{tabular}{|c|c|c|c|}
\hline & $\begin{array}{l}\text { Emotional } \\
\text { competence }\end{array}$ & $\begin{array}{l}\text { Investment } \\
\text { knowledge }\end{array}$ & $\begin{array}{l}\text { Overall investment } \\
\text { competence }\end{array}$ \\
\hline Income 20,000-50,000 Euro & $\begin{array}{l}-0.126^{* * *} \\
(0.046)\end{array}$ & $\begin{array}{l}-0.063^{*} \\
(0.033)\end{array}$ & $\begin{array}{l}-0.190 * * * \\
(0.055)\end{array}$ \\
\hline Income $50,000-80,000$ Euro & $\begin{array}{l}-0.130 * * * \\
(0.047)\end{array}$ & $\begin{array}{l}-0.031 \\
(0.034)\end{array}$ & $\begin{array}{l}-0.172^{* * * *} \\
(0.056)\end{array}$ \\
\hline Wealth: no statement & $\begin{array}{l}0.120 * \\
(0.067)\end{array}$ & $\begin{array}{l}-0.060 \\
(0.048)\end{array}$ & $\begin{array}{l}0.102 \\
(0.080)\end{array}$ \\
\hline Wealth $<30,000$ Euro & $\begin{array}{l}0.082 * \\
(0.047)\end{array}$ & $\begin{array}{l}-0.053 \\
(0.034)\end{array}$ & $\begin{array}{l}0.040 \\
(0.057)\end{array}$ \\
\hline Wealth 30,000-70,000 Euro & $\begin{array}{l}-0.032 \\
(0.050)\end{array}$ & $\begin{array}{l}-0.017 \\
(0.036)\end{array}$ & $\begin{array}{l}-0.036 \\
(0.060)\end{array}$ \\
\hline Wealth 70,000-100,000 Euro & $\begin{array}{l}-0.051 \\
(0.063)\end{array}$ & $\begin{array}{l}0.002 \\
(0.045)\end{array}$ & $\begin{array}{l}-0.030 \\
(0.076)\end{array}$ \\
\hline Trainee & $\begin{array}{l}-0.060 \\
(0.120)\end{array}$ & $\begin{array}{l}-0.070 \\
(0.088)\end{array}$ & $\begin{array}{l}-0.174 \\
(0.147)\end{array}$ \\
\hline Company manager (leading position) & $\begin{array}{l}0.207 * * \\
(0.088)\end{array}$ & $\begin{array}{l}-0.025 \\
(0.063)\end{array}$ & $\begin{array}{l}0.158 \\
(0.106)\end{array}$ \\
\hline Team manager (leading position) & $\begin{array}{l}-0.003 \\
(0.045)\end{array}$ & $\begin{array}{l}0.009 \\
(0.032)\end{array}$ & $\begin{array}{l}-0.010 \\
(0.054)\end{array}$ \\
\hline Assistant & $\begin{array}{l}-0.100^{* *} \\
(0.050)\end{array}$ & $\begin{array}{l}0.010 \\
(0.036)\end{array}$ & $\begin{array}{l}-0.079 \\
(0.060)\end{array}$ \\
\hline Job-seeking & $\begin{array}{l}0.001 \\
(0.061)\end{array}$ & $\begin{array}{l}0.013 \\
(0.043)\end{array}$ & $\begin{array}{l}0.022 \\
(0.073)\end{array}$ \\
\hline Self-employment & $\begin{array}{l}-0.086^{*} \\
(0.044)\end{array}$ & $\begin{array}{l}0.016 \\
(0.032)\end{array}$ & $\begin{array}{l}-0.076 \\
(0.053)\end{array}$ \\
\hline Other professional activity & $\begin{array}{l}0.022 \\
(0.038)\end{array}$ & $\begin{array}{l}0.033 \\
(0.027)\end{array}$ & $\begin{array}{l}0.061 \\
(0.045)\end{array}$ \\
\hline Constant & $\begin{array}{l}-0.612 * * * \\
(0.091)\end{array}$ & $\begin{array}{l}-0.526^{* * *} \\
(0.065)\end{array}$ & $\begin{array}{l}-1.202^{* * *} \\
(0.109)\end{array}$ \\
\hline$N$ & 1917 & 1911 & 1897 \\
\hline
\end{tabular}

The table reports regional differences in estimated investment competence based on a weighted scale as well as marginal effects of control variables after robust regressions. The base categories are: low importance of the own advisor's opinion, age 25-30, male, no higher education, no real estate ownership, income $>80,000$ Euro, financial wealth $>100,000$ Euro, team member (executive position). Robust standard errors are reported in parentheses

$*, * *$, and $* * *$ denote significance at the 10,5 , and $1 \%$ level, respectively 
Table 13 Regional differences in investment competence based on all questions

\begin{tabular}{|c|c|c|}
\hline $\begin{array}{l}\text { Table } 13 \text { Regional differences } \\
\text { in investment competence based } \\
\text { on all questions }\end{array}$ & & $\begin{array}{l}\text { Overall investment competence } \\
\text { (number of mistakes) }\end{array}$ \\
\hline & SwissG-G & $\begin{array}{l}-0.604 * * * \\
(0.105)\end{array}$ \\
\hline & SwissF-F & $-0.889 * * *$ \\
\hline The table reports regional & & $(0.145)$ \\
\hline $\begin{array}{l}\text { differences in the predicted } \\
\text { number of mistakes based on all } \\
\text { questions (including the }\end{array}$ & SwissI-I & $\begin{array}{l}-0.633 * * * \\
(0.179)\end{array}$ \\
\hline $\begin{array}{l}\text { internally inconsistent } \\
\text { questions) after robust }\end{array}$ & SwissF-SwissG & $\begin{array}{l}0.291 * \\
(0.128)\end{array}$ \\
\hline $\begin{array}{l}\text { regressions with controls. All } \\
\text { tests are adjusted for multiple } \\
\text { comparisons by the Bonferroni }\end{array}$ & SwissI-SwissG & $\begin{array}{l}0.467 * * \\
(0.168)\end{array}$ \\
\hline $\begin{array}{l}\text { method. Robust standard errors } \\
\text { are reported in parentheses } \\
*, * * \text {, and } * * * \text { denote }\end{array}$ & SwissI-SwissF & $\begin{array}{l}0.176 \\
(0.194)\end{array}$ \\
\hline nificance at the 10,5 , and $1 \%$ & Method & Robust regression $(N=1933)$ \\
\hline
\end{tabular}

Overall investment competence (number of mistakes)

\section{References}

Acker, D., Duck, N.W.: Cross-cultural overconfidence and biased self-attribution. J. Socio Econ. 37, 18151824 (2008)

Barber, B.M., Lee, Y.T., Liu, Y.J., Odean, T.: Just how much do individual investors lose by trading? Rev. Financ. Stud. 22(2), 609-632 (2009)

Barberis, N., Xiong, W.: Realization utility. J. Financ. Econ. 104(2), 251-271 (2012)

Barber, B.M., Odean, T.: Trading is hazardous to your wealth: the common stock investment performance of individual investors. J. Finance 55(2), 773-806 (2000)

Behrman, J.R., Mitchell, O.S., Soo, C., Bravo, D.: How financial literacy affects household wealth accumulation. Am. Econ. Rev. 102(3), 300-304 (2012)

Blume, M., Friend, I.: The allocation of wealth to risky assets-the asset structure of individual portfolios and some implications for utility functions. J. Finance 30, 585-603 (1975)

Bowles, S.: Endogenous preferences: the cultural consequences of markets and other economic institutions. J. Econ. Lit. 36(1), 75-111 (1998)

Brinson, G.P., Hood, L.R., Beebower, G.L.: Determinants of portfolio performance. Financ. Anal. J. 42(4), 39-44 (1986)

Brown, M., Graf, R.: Financial literacy and retirement planning in Switzerland. Numeracy 6(2), 619-635 (2013)

Brügger, B., Lalive, R., Zweimüller, J.: Does Culture Affect Unemployment? Evidence from the Röstigraben. IZA Discussion Papers. Retrieved from (2009) http://ideas.repec.org/p/iza/izadps/dp4283. html

Calvet, L.E., Campbell, J.Y., Sodini, P.: Measuring the financial sophistication of households. Am. Econ. Rev. 99, 393-398 (2009)

Charness, G., Levin, D.: When optimal choices feel wrong: a laboratory study of Bayesian updating, complexity, and affect. Am. Econ. Rev. 95(4), 1300-1309 (2005)

Chen, M.K.: The effect of language on economic behavior: evidence from saving rates, health behaviors and retirement assets. Am. Econ. Rev. 103(2), 690-731 (2013)

Esser, F., Umbricht, A.: Competing models of journalism? Political affairs coverage in US, British, German, Swiss, French and Italian newspapers. Journalism 14, 989-1007 (2013) 
Eugster, B., Parchet, R.: Culture and Taxes: Towards Identifying Tax Competition. Cahiers de Recherches Economiques du Département d'Econométrie et d'Economie politique (DEEP) (2013)

Eugster, B., Lalive, R., Stienhauer, A., Zweimueller, J.: The demand for social insurance: does culture matter? Econ. J. 121, 413-448 (2011)

Fehr, E., Ho, K.: Introduction: tastes, castes and culture: the influence of society on preferences. Econ. J. 121, 396-412 (2011)

Feld, L.P., Kirchgassner, G.: Direct Democracy, Political Culture, and the Outcome of Economic Policy?: A Report on the Swiss Experience. Working Paper, University of St. Gallen (2000)

Gilovich, T., Wang, R.F., Regan, D., Nishina, S.: Regrets of action and inaction across cultures. J. Cross Cult. Psychol. 34(1), 61-71 (2003)

Goetzmann, W.N., Kumar, A.: Equity portfolio diversification. Rev. Finance 12, 433-463 (2008)

Henrich, J.: Does culture matter in economic behavior? Ultimatum game bargaining among the Machiguenga of the Peruvian Amazon. Am. Econ. Rev. 90(4), 973-979 (2000)

Hoff, K., Kshetramade, M., Fehr, E.: Caste and punishment: the legacy of caste culture in norm enforcement? Econ. J. 121(556), 449-475 (2011)

Kelly, M.: All their eggs in one basket: portfolio diversification of US households. J. Econ. Behav. Organ. 27, 87-96 (1995)

King, R.D.: Should English be the law? Atl. Mon. 279(4), 55-64 (1997)

Koestner M., Meyer, S., Hackethal, A.: Do Individual Investors Learn from Their Mistakes? SSRN Working Paper 2122652 (2012)

Kuo, M.-H., Chen, S.K., Chen, S.-S.: How to lessen the disposition effect? It pays to study before investing. Adv. Bus. Manag. Forecast. 9, 77-90 (2013)

Lehenkari, M.: In search of the underlying mechanism of the disposition effect. J. Behav. Decis. Mak. 16, 196-209 (2012)

Levin, I.P., Gaeth, G.J., Evangelista, F., Albaum, G., Schreiber, J.: How positive and negative frames influence the decisions of persons in the United States and Australia. Asia Pac. J. Mark. Logist. 13(2), 64-71 (2001)

Levinson, J.D., Peng, K.: Valuing cultural differences in behavioral economics. Psychology 4(1), 32-47 (2007)

Liu, Y.-J., Tsai, C.-L., Wang, M.-C., Zhu, N.: Prior consequences and subsequent risk taking: new field evidence from the Taiwan Futures Exchange. Manag. Sci. 56(4), 606-620 (2010)

Longchamp, C.: Drei Reaktionsweisen im Spannungsfeld von Moderne und Tradition: Eine Analyse polit-kultureller Konflikte in der Schweiz am Vorabend der Expo. 02. GfS-Research Institute, Bern (2002)

Lusardi, A., Mitchell, O.: The Economic Importance of Financial Literacy. NBER Working Paper 18952 (2013)

McRae, K.: Conflict and Compromise in Multilingual Societies: Switzerland. Wilfried Laurier University Press, Waterloo (1983)

Miauton, M.H., Reymond, A.: Der nationale Zusammenhalt: Mythus oder Realität? Ansichten der Leader und der Bevölkerung. M.I.S. Trend S.A., Lausanne, Lausanne (1998)

Nisbett, R.E., Peng, K.P., Choi, I., Norenzayan, A.: Culture and systems of thought: holistic versus analytic cognition. Psychol. Rev. 108, 291-310 (2001)

Nisbett, R.E.: The Geography of Thought. Free Press, New York (2003)

Odean, T.: Are investors reluctant to realize their losses? J. Finance 53, 1775-1798 (1998)

Schiendorfer, A.: Switzerland: the end of uncertainty. Credit Suisse Bull. 5 (2013) https://www.credit-suisse. com/us/en/articles/articles/news-and-expertise/2013/12/en/switzerland-the-end-of-uncertainty.html

Shefrin, H., Statman, M.: The disposition to sell winners too early and ride losers too long: theory and evidence. J. Finance 40, 777-790 (1985)

Spina, R.R., Ji, L.J., Guo, T., Zhang, Z., Ye, L., Fabrigar, L.: Cultural differences in the representativeness heuristic: expecting a correspondence in magnitude between cause and effect. Personal. Soc. Psychol. Bull. 36(5), 583-597 (2010)

Stulz, R.M., Williamson, R.: Culture, openness, and finance. J. Financ. Econ. 70(3), 313-349 (2003)

Summers, B., Duxbury, D.: Decision-dependent emotions and behavioral anomalies. Organ. Behav. Hum. Decis. Process. 118(2), 226-238 (2012)

Tversky, A., Kahneman, D.: Availability: a heuristic for judging frequency and probability. Cogn. Psychol. 5(2), 207-232 (1973)

Vulkan, N.: An economist's perspective on probability matching. J. Econ. Surv. 14, 101-118 (2000) 
Wang, M., Fischbeck, P.S.: Similar in how to frame, but different in what to choose. Mark. Bull. 15, 13-24 (2004)

West, J., Graham, J.L.: A linguistic-based measure of cultural distance and its relationship to managerial values. Manag. Int. Rev. 44(3), 239-260 (2004)

Wright, G.N., Phillips, L.D.: Cultural variation in probabilistic thinking: alternative ways of dealing with uncertainty. Int. J. Psychol. 15(4), 239-257 (1980)

Yates, J.F., Ronis, D., Wang, D.: Probability judgment accuracy: China, Japan and the United States. Organ. Behav. Hum. Decis. Process. 43, 145-171 (1989)

Yates, J.F., Lee, J.-W., Shinotsuka, H., Patalano, A.L., Sieck, W.R.: Cross-cultural variations in probability judgment accuracy: beyond general knowledge overconfidence. Organ. Behav. Hum. Decis. Process. 74, 89-117 (1998)

Kremena Bachmann is a Senior Research Associate at the Department of Banking and Finance of the University of Zurich. She specializes in research on behavioral finance and financial decision-making. Her research focus is the impact of cognitive and emotional factors on financial decision-making and on the importance of financial advice in improving the decision quality of individual investors. Dr. Bachmann earned a master's degree in economics from the University of St. Gallen (HSG) and a Ph.D. in finance with a focus on behavioral finance from the Swiss Finance Institute.

Thorsten Hens is a Swiss Finance Institute Professor at the University of Zurich's Department of Banking and Finance, which he headed from 2007 to 2015. His research on behavioral finance has achieved international recognition and is a source of leadership in academia and practice. Thorsten Hens has published more than 50 refereed articles in renowned journals like Econometrics, Review of Economic Studies, Management Science, and Journal of Financial and Quantitative Analysis. He applies his research in the HSG and UZH spin-off company Behavioral Finance Solutions GmbH. 